\title{
Trace Gas/Aerosol Boundary Concentrations and their Impacts on Continental-Scale AQMEII Modeling Domains
}

Kenneth Schere $^{\mathrm{a}^{*}}$, Johannes Flemming ${ }^{\mathrm{b}}$, Robert Vautard ${ }^{\mathrm{c}}$, Charles Chemel ${ }^{\mathrm{d}, \mathrm{e}}$, Augustin Colette ${ }^{\mathrm{f}}$, Christian Hogrefe ${ }^{\mathrm{g}}$, Bertrand Bessagnet ${ }^{\mathrm{f}}$, Frederik Meleux ${ }^{\mathrm{f}}$, Rohit Mathur ${ }^{\mathrm{a}}$, Shawn Roselle ${ }^{\mathrm{a}}$, Rong-Ming Hu ${ }^{\text {e }}$, Ranjeet S. Sokhi ${ }^{\text {e }}$ S.T. Rao ${ }^{\text {a }}$, Stefano Galmarini ${ }^{\text {h }}$

${ }^{a}$ Atmospheric Modeling and Analysis Division, National Exposure Research Laboratory, Office of Research and Development, US Environmental Protection Agency, Research Triangle Park, NC 27711, USA

${ }^{\mathrm{b}}$ European Centre for Medium-Range Weather Forecasts (ECMWF), Reading, UK

${ }^{c}$ Laboratoire des Sciences du Climat et de l'Environnement, IPSL, CEA/CNRS/UVSQ, Gif/Yvette, FRANCE

${ }^{\mathrm{d}}$ National Centre for Atmospheric Science (NCAS), Centre for Atmospheric \& Instrumentation Research (CAIR), University of Hertfordshire, Hatfield, UK

${ }^{\mathrm{e}}$ Centre for Atmospheric \& Instrumentation Research (CAIR), University of Hertfordshire, Hatfield, UK

f Institut National de l' Environnement Industriel et des Risques (INERIS), Parc Technologique Alata, Verneuil en Halatte, FRANCE

${ }^{\mathrm{g}}$ Bureau of Air Quality Analysis and Research, New York State Department of Environmental Conservation, Albany, NY 12233, USA

${ }^{\mathrm{h}}$ European Commission-Joint Research Center, Institute for Environment and Sustainability, I-21027 Ispra, ITALY

*Corresponding author: Tel: +01-919-5413795; fax: +01-919-5411379. E-mail:

schere.kenneth@epa.gov. U.S. EPA-E243-04, Research Triangle Park, NC 27711 USA

(Submitted to Atmospheric Environment: 6 May 2011) 


\section{Abstract}

3 Over twenty modeling groups are participating in the Air Quality Model Evaluation International

4 Initiative (AQMEII) in which a variety of mesoscale photochemical and aerosol air quality

5 modeling systems are being applied to continental-scale domains in North America and Europe

6 for 2006 full-year simulations for model inter-comparisons and evaluations. To better

7 understand the reasons for differences in model results among these participating groups, each

8 group was asked to use the same source of emissions and boundary concentration data for their

9 simulations. This paper describes the development and application of the boundary

10 concentration data for this AQMEII modeling exercise. The European project known as GEMS

11 (Global and regional Earth-system Monitoring using Satellite and in-situ data) has produced

12 global-scale re-analyses of air quality for several years, including 2006 (http://gems.ecmwf.int).

13 The GEMS trace gas and aerosol data were made available at 3-hourly intervals on a regular

14 latitude/longitude grid of approximately 1.9-degree resolution within 2 "cut-outs" from the

15 global model domain. One cut-out was centered over North America and the other over Europe,

16 covering enough spatial domain for each modeling group to extract the necessary time- and

17 space-varying (horizontal and vertical) concentrations for their mesoscale model boundaries.

18 Examples of the impact of these boundary concentrations on the AQMEII continental

19 simulations are presented to quantify the sensitivity of the simulations to boundary conditions.

20 In addition, some participating groups were not able to use the GEMS data and instead relied

21 upon other sources for their boundary concentration specifications. These are noted, and the

22 contrasting impacts of other data sources for boundary data are presented. How one specifies

23 four-dimensional boundary concentrations for mesoscale air quality simulations can have a

24 profound impact on the model results, and hence, this aspect of data preparation must be

25 performed with considerable care.

27 Keywords: air quality modeling, boundary concentrations, model evaluation, AQMEII, GEMS 


\section{Introduction}

The evaluation of regional- through continental-scale photochemical and aerosol air quality simulation modeling systems (PAQMs) has been a subject of considerable interest in recent years (Dennis et al., 2010; Vautard et al., 2007; McKeen et al., 2005). Such systems have been adopted by the air quality management and forecasting communities to provide estimates of future (10 years and longer) air quality based on planned emissions mitigation actions, as well as forecasts of short-term (1-3 days) air quality for public notice and alerts (Honoré et al., 2009; Eder et al., 2010). The results from these model applications have become increasingly visible and significant from the standpoint of public perceptions as well as having considerable economic, political, and social implications. Therefore, it is necessary that users of the models

and consumers of the model results have sufficient confidence in these tools and their predictions

42 to use for the intended applications. Such confidence can be obtained, in part, from evaluations

43 of the models against real-world measurements for their particular applications.

44 To better foster a structured and coordinated approach to the PAQM evaluations at the international level, an Air Quality Model Evaluation International Initiative (AQMEII) was launched in 2008 as a collaboration between North American and European modeling groups (Rao et al., 2011; http://aqmeii.jrc.ec.europa.eu). AQMEII is aimed at providing a permanent forum to constantly monitor the state of advancement of regional-scale PAQMs and model evaluation methodologies through the organization of periodic workshops and modeling activities in which the different aspects of model performance evaluation are considered. In the first phase of AQMEII, an initial exercise has been launched in which more than twenty modeling groups in North America and Europe are using their regional-scale PAQMs to simulate

53 a full-year (2006) retrospective continental application. Each participating group has been

54 requested to model both continents using common reference model input data sets, namely the

55 gridded source emissions and the lateral boundary concentrations for each continent. The focus 56 of the study is on the application of the structured model evaluation framework discussed in 57 Dennis et al. (2010) to these model simulation results, using a comprehensive observational 58 database consisting of surface, aircraft, and satellite data for model evaluation and model inter59 comparison. 
This paper describes the development of a set of prescribed boundary concentrations for each continental model domain for use by all AQMEII modelers for this exercise, as well as some of the major impacts of these boundary concentrations on model results. Regional- or even continental-scale geographical extents of modeling domains require careful specification of the

64 vertical and horizontal profiles of boundary concentrations since typical airflows over North 65 America and Europe can traverse each continent in a few days to a week. The trace gas and aerosol concentrations as specified at the model's boundaries will affect the model simulation

67 results as this material is transported into the simulation domains and interacts with the model's

68 internal processing of emissions, chemical transformations, deposition, etc. For this AQMEII

69 exercise the minimum spatial extent of each continent to be modeled by all participants is

70 defined by latitude/longitude boundaries:

71 North America: $\quad$ Latitude: $25.5^{\circ} \mathrm{N}$ to $58.5^{\circ} \mathrm{N} \quad$ Longitude: $130^{\circ} \mathrm{W}$ to $59.5^{\circ} \mathrm{W}$

72 Europe: Latitude: $35.0^{\circ} \mathrm{N}$ to $70.0^{\circ} \mathrm{N}$ Longitude: $15.0^{\circ} \mathrm{W}$ to $35^{\circ} \mathrm{E}$

73 (See Figures 1 and 2 in Rao et al., 2011.)

\section{GEMS Re-analysis}

A variety of sources is used to specify boundary concentrations for retrospective regionalscale PAQM simulations. Ideally, observational data should be of sufficient density and quality to provide these specifications. However, model domain boundaries are often over the ocean or sparsely-monitored land areas. Satellite-based platforms provide data for only a few chemical species and only intermittently in space and time. Global-scale PAQMs of coarser resolution are

82 another source for providing boundary concentrations to regional-scale models. For the

83 AQMEII project, a combination of global-scale models with assimilation of satellite-based

84 observational data was used to derive boundary concentrations. This hybrid analysis using 85 model and observational data for a retrospective assessment is commonly referred to as "re86 analysis". In this case, data were derived from a multi-year re-analysis that included the target

87 year of 2006 from the European Union-funded project of Global and regional Earth-system

88 Monitoring using Satellite and in-situ data (GEMS; http://gems.ecmwf.int; Hollingsworth et al., 89 2008; GEMS, 2010). 
The GEMS project was set up by thirty-one participating institutions coordinated by the

91 European Centre for Medium-Range Weather Forecasts (ECMWF) to build and demonstrate the

92 core capability for providing a comprehensive range of services related to the chemical and

93 particulate matter composition of the atmosphere. Among the demonstrated capabilities were

94 data analyses and modeling systems for monitoring global distributions of atmospheric

95 constituents, with focus areas of climate, air quality, and ultraviolet radiation, especially as they

96 affect European communities. Global re-analysis products from GEMS are available for the

97 period 2003-2008. These re-analyses make use of satellite observations allowing the retrieval of

$98 \mathrm{O}_{3}, \mathrm{CO}, \mathrm{CH}_{4}, \mathrm{CO}_{2}$, and aerosol optical depth during the AQMEII period of interest. Although

99 GEMS is now concluded, the work conducted therein is being extended and improved through

100 the new Monitoring Atmospheric Composition and Climate project (MACC; http://www.gmes-

101 atmosphere.eu).

102 Figure 1 illustrates the principal components of the GEMS global modeling system. The

103 GEMS system was built within and around the ECMWF Integrated Forecasting System (IFS;

$104 \mathrm{http} / /$ www.ecmwf.int/research/ifsdocs/), a global operational weather forecasting model system,

105 including the capability for four-dimensional variational data assimilation (Rabier et al., 2000).

106 The IFS system is coupled with one of three global chemical transport models (CTMs):

107 MOZART3 (Kinnison et al., 2007), MOCAGE (Bousserez et al., 2007), or TM5 (Huijnen et al.,

108 2010) through a special-purpose OASIS4 software coupler (Flemming et al., 2009). The main

109 idea behind the coupled system is that the IFS computes only the transport of the assimilated

110 reactive gases while the tendencies due to chemical conversion, deposition and emission

111 injection are provided by one of the CTMs. The simulation of global aerosol and greenhouse

112 gases is directly included within the IFS model (Morcrette et al., 2009). In this way, the IFS

113 needs to handle only five additional chemical tracers, while the comprehensive schemes of the

114 CTMs contain between 55 and 118 gaseous species. The coupled CTM is driven by

115 meteorological data from the IFS with a coupling frequency of one hour. For the AQMEII

116 application, it is principally the IFS-MOZART3 configuration whose data has been processed for

117 regional-scale model boundary concentrations.

118 The IFS uses a T159 spectrally-resolved global grid with a horizontal grid box size of about

$119125 \mathrm{~km}$. MOZART-3 uses a regular latitude/longitude grid of $1.875^{\circ} \times 1.875^{\circ}$. The coupler

120 performs horizontal bi-linear interpolations between the meteorological and CTM horizontal 
121 grids. The vertical coordinate is given by 60 hybrid-sigma pressure levels, with a model top at $1220.1 \mathrm{hPa}$. The same vertical coordinate is used by the IFS and all CTMs in the GEMS system to 123 avoid the need for vertical interpolations. The coupling interval is $3600 \mathrm{~s}$ which is the largest

124 acceptable time step for the IFS at a T159 resolution. Output is saved at 3-h intervals from the 125 model simulations. Source emissions for the MOZART-3 global simulations are specified as 126 monthly averages for a base year of 2000 for anthropogenic trace gases (RETRO database;

127 Schultz et al., 2009) and aerosols (EDGAR, http://www.pbl.nl/en/themasites/edgar/ index.html;

128 SPEW, Bond et al., 2004). Eight-day average fire emissions for the 2006 model application year

129 are derived from the Global Fire Emissions Database (GFEDv2; van der Werf et al., 2006).

130 Biogenic, sea salt, and dust emissions are parameterized within the model based on 131 meteorological inputs (GEMS, 2010).

132 The advantage of using the GEMS re-analysis data to provide boundary concentrations for 133 AQMEII simulations compared to other global model outputs is that the GEMS results include 134 the assimilation of observed data derived from satellite platforms. Figure 2 indicates the satellite 135 data usage during the GEMS project, with the AQMEII target year of 2006 highlighted. There 136 were multiple instruments available for measuring portions of the ozone $\left(\mathrm{O}_{3}\right)$ column during 137 2006, including from SCIAMACHY, SBUV-2, and MLS instruments. Taken together these data 138 provide some vertical resolution to the $\mathrm{O}_{3}$ column, with greatest fidelity in the stratosphere and 139 upper troposphere (Flemming et al., 2011). In addition, $\mathrm{CO}$ columns are available from the 140 MOPITT instrument, and aerosol optical depths (AODs) are derived from the MODIS 141 instruments onboard the Terra and Aqua satellites. Information on atmospheric aerosols can be 142 derived from the AOD retrievals. Complete details on the data assimilation system and 143 implementation for GEMS can be found in Benedetti et al., 2009 and Inness et al., 2009.

144 The GEMS re-analysis outputs for 2006 were further processed by ECMWF for AQMEII use 145 by interpolating all requested data for selected variables at 3-h intervals on a regular 146 latitude/longitude $\left(1.875^{\circ} \mathrm{X} 1.875^{\circ}\right)$ grid within specific geographical "cut-outs" from the global 147 model domain. These cut-outs for Europe and for North America are illustrated in Figure 3. The 148 spatial extent of each cut-out extends well beyond the minimum domain sizes specified for 149 AQMEII regional/continental domains such that AQMEII participants could use the data within 150 the global cut-outs to derive the boundary concentrations for their own model exercises. Data 151 from the lowest 47 IFS model layers (surface through 10hPa) were extracted within each cut-out 
152 over a full time period of 1 December 2005 through 31 December 2006, allowing for sufficient 153 model spin-up time for the 2006 simulation. Table 1 lists the chemical and aerosol species

154 extracted for AQMEII use. These data were archived and made available to AQMEII 155 participants by collaborators in Météo-France.

156 Air quality modelers participating in AQMEII then are able to access these GEMS data and 157 use them for specification of boundary concentrations. There are, however, additional 158 assumptions and processing steps involved before the data can be used by the regional models.

159 The GEMS data must be spatially interpolated for the boundaries of each regional model's native 160 grid and temporally interpolated from the 3 -h output interval to the 1-h boundary updates 161 typically employed by the regional models. Also, the GEMS data contain fairly coarse chemical 162 speciation of the gaseous organic compounds. Additional disaggregation of these organic 163 compounds into the specific organic classes used by the tropospheric atmospheric chemistry 164 mechanisms is usually necessary. In addition, the GEMS aerosol data for sea salt and dust may 165 need to be redistributed based on the size distribution information carried within the regional 166 model. Finally, the GEMS data provide information for most of the chemical and aerosol 167 species needed at the models' boundaries that have significant transport influence. However, all 168 species are not included in the GEMS data. Modelers may need to provide another source of 169 boundary concentration data for aerosol sulfate and nitrate, for example, and additional gas170 phase species that may be in their model, unless the boundaries are assumed to be zero, zero171 gradient, or some fixed concentration.

172 There are a few caveats to note with regards to the use of the GEMS data for AQMEII. First, 173 the $\mathrm{SO}_{2}$ concentrations were calculated within IFS as a tracer using simple assumptions of 174 emissions and prescribed loss. No chemical transformations were considered.

175 Recommendations were made to AQMEII modelers to use the $\mathrm{SO}_{2}$ data with caution. Sea salt 176 estimates were made as a function of wind speed and other environmental parameters in the IFS 177 model. Based on evaluation of the GEMS sea salt data for 2003, quite significant 178 overpredictions of sea salt aerosol (over 400\%) were observed over North America (GEMS, 179 2010). Preliminary analysis showed this to be true for 2006 as well, so AQMEII modelers were 180 cautioned on the GEMS sea salt values. Estimates for sea salt over Europe, however, did not 181 show these same tendencies for overestimation. In addition, organic carbon emissions from fires 182 in the GEMS data set may have been overestimated in the lower model layers due to the lack of a 
183 plume-rise mechanism in the model and an overestimated persistence of the fires from the 8-day

184 resolution in the data being assimilated into the model. Cautions were therefore extended

185 regarding the organic carbon data from large fires for AQMEII use.

\section{Other Sources of Boundary Concentrations}

188 The modeling protocol for the AQMEII 2006 model simulations requested that participants 189 derive their boundary concentrations from the GEMS re-analysis data described above.

190 However, not all participants adhered strictly to this request. In fact, there were a variety of 191 sources that were accessed for the continental-scale model boundary concentrations. Table 2

192 presents examples of the various modeling systems used and the source of boundary

193 concentration data in each instance. These data sources include other hemispheric and global

194 modeling systems, as well as climatological or "background" tropospheric concentrations.

195 Ideally, if all participants had used the same source for the boundary concentration data, as well

196 as a common source for the emissions data, the data analysis and interpretation for the project

197 would be assisted by minimizing confounding effects of different sources of data on model

198 results. Some groups used the requested GEMS data source, as well as alternate sources,

199 providing the data for sensitivity studies on the effect of alternate sources of boundary

200 concentrations on their model simulations.

\section{Impact of Boundary Concentrations on Continental Simulations}

With typical wind speeds across North America and Europe, inflow air masses can traverse each continent within as few as 3-5 days. Thus the specification of inflow air quality boundary

206 concentrations has the potential for significant impacts on continental model simulations, 207 especially in areas of weaker internal model forcing from source emissions and atmospheric 208 chemistry, and for chemical compounds having lifetimes of this order of magnitude. Pfister et al.

209 (2011) used aircraft and satellite data during the ARCTAS-CARB field campaign during the 210 summer of 2008 to evaluate the MOZART-4 global chemical transport model's simulation 211 results for its chemical representativeness of chemical inflow to the U.S. west coast. The global 212 model was shown to capture only about half of the observed free tropospheric air pollution 213 variability. Sensitivity simulations with the regional WRF-Chem model, performed as part of 
214 the cited work, also showed that the temporal variability in the pollution inflow does clearly

215 impact modeled surface concentrations over California. It was suggested that time- and space-

216 varying chemical boundary conditions from global models provide useful input to regional

217 models, but likely still lead to an underestimate of peak surface concentrations and the variability

218 associated with long-range transport of air pollution.

219 Hogrefe et al. (2011) performed long-term simulations with the Community Multiscale Air

220 Quality (CMAQ) model using two sets of chemical boundary conditions, one derived from time-

221 invariant climatological vertical profiles and the other one from a global chemistry model. The

222 comparison of both simulations revealed that lateral boundary conditions have a significant

223 impact on a regional air quality model's ability to simulate long-term $\mathrm{O}_{3}$ variability and trends,

224 especially for the middle and lower percentiles of the $\mathrm{O}_{3}$ distribution. As an illustration, Figure 4

225 shows time series of May - September average daily maximum 1-h $\mathrm{O}_{3}$ concentrations derived

226 from observations and these two sets of CMAQ simulations for the time period from 1988 to

227 2005. It can be seen that the choice of boundary conditions affects the magnitude of the mean

228 concentrations as well as their inter-annual variability and trends. In this particular example, the

229 CMAQ simulation using the time-invariant boundary conditions shows better agreement with the

230 observations in terms of absolute concentrations and trends while the CMAQ simulation using

231 boundary conditions derived from the global model shows better agreement in terms of inter-

232 annual variability.

233 Li et al. (2002) used a five-year (1993-1997) simulation with the GEOS-Chem CTM and

234 showed that North American pollution enhances surface $\mathrm{O}_{3}$ in continental Europe by 2-4 ppbv

235 on average in summer and by $5-10 \mathrm{ppbv}$ during transatlantic transport events. Specifying the

236 model continental-scale $\mathrm{O}_{3}$ boundary concentrations correctly is significant in that the North

237 American influence on surface $\mathrm{O}_{3}$ in Europe is particularly strong at the thresholds used for the

238 European air quality standards (55-65 ppbv). Simulating the daily variability of $\mathrm{O}_{3}$ boundary

239 concentrations was also shown to significantly improve both variability and biases of simulated

240 daily $\mathrm{O}_{3}$ maxima in Europe, in particular for the most frequent non-extreme values (Szopa et al., 241 2009).

242 Ratigejev et al. (2010) demonstrate that global CTMs have difficulty reproducing synoptic243 scale pollution plumes during long-range transport. Numerical diffusion interacting with non244 uniform atmospheric flows dissipates the plumes faster than ambient observations suggest. The 
245 authors state that novel numerical methods, such as adaptive grids or embedded Lagrangian 246 plumes, may circumvent the problem of accurately sustaining the plume integrity. Makar et al.

247 (2010) evaluated ten different approaches for applying lateral and top climatological boundary

248 concentrations for $\mathrm{O}_{3}$ using the AURAMS regional CTM. They found that dynamic adjustments

249 to the $\mathrm{O}_{3}$ profile in response to the model-estimated tropopause height were needed to better 250 match mass consistency between chemical and meteorological models. Their results highlight

251 the importance of evaluating boundary concentrations and mass consistency/correction

252 algorithms with three-dimensional measurements.

\subsection{CMAQ Model - North America application}

255 The U.S. EPA contributed results to AQMEII from a 2006 North American simulation from 256 their CMAQ model. The model domain included all of the continental U.S. (except Alaska), 257 southern Canada, and northern Mexico. Meteorological data for the CMAQ simulation were 258 derived from a continental model run of the Weather Research and Forecasting (WRF) model 259 using four-dimensional data assimilation. The CMAQ model also made use of the standard 260 protocol data provided by AQMEII for emissions and boundary concentrations (GEMS dataset).

261 To assess the adequacy of the GEMS data for providing inflow $\mathrm{O}_{3}$ boundary concentrations, we 262 have examined the performance of the CMAQ model using observed data from the INTEX-B 263 Ozonesonde Network Study (IONS) of 2006 (Tarasick et al., 2010) for sounding locations near 264 the west (inflow) coast of North America. The IONS 2006 study provided a total of 740 265 ozonesonde profiles from 23 sites across North America. Figure 5 illustrates the locations of 266 these sites within the CMAQ modeling domain, with the shaded area indicating the region of 267 interest for examining the boundary concentration impacts.

268 Figures $6 \mathrm{a}$ and $6 \mathrm{~b}$ present the results of the CMAQ simulation and the observed $\mathrm{O}_{3}$ vertical 269 profile from the Trinidad Head site on the northern California coast averaged over all March $270 \quad(n=6)$ and August $(n=30)$ profiles, respectively. For both months, the model and observed 271 profiles agree fairly well at altitudes corresponding to the upper troposphere and stratosphere.

272 Here, the model is greatly influenced by the boundary concentrations as there are no local 273 emissions and little atmospheric chemistry to influence the estimated concentrations. However, 274 in the lower and mid troposphere, the model significantly underestimates the $\mathrm{O}_{3}$ concentrations 275 compared to the observed profile. Also indicated on the figures are the concentrations from 
276 CMAQ attributable to a boundary concentration tracer for $\mathrm{O}_{3}$. In these calculations, the impact

277 of the spatially and temporally varying $\mathrm{O}_{3}$ boundary conditions was tracked using a tracer

278 species that underwent advective, turbulent, and cloud transport, and wet and dry deposition

279 similar to $\mathrm{O}_{3}$. Since the tracer was not subject to any chemical loss, its inferred impact on the net

280 simulated $\mathrm{O}_{3}$ may be slightly overestimated. Nevertheless, the tracer provides a direct estimate

281 of the impact of the GEMS boundary concentrations on simulated $\mathrm{O}_{3}$ distributions and trends.

282 With little local photochemistry occurring in March, it is evident that the lower portion of the

283 profile is completely controlled by the boundary concentrations, while in August with more

284 active photochemistry the lowest portion of the profile shows enhanced concentrations as

285 compared to the boundary tracer. This is further illustrated in Figure 7 which presents the

286 average fractional contribution of the boundary conditions to the simulated vertical profile at

287 Trinidad Head for the months of March and August 2006. It is evident that above 3-4 km the

288 simulated $\mathrm{O}_{3}$ variability is largely dictated by the boundary condition specification.

289 Similar analyses for the Kelowna site in British Columbia, Canada are presented in Figure 8.

290 (There were 2 profiles available in March and 26 in August at Kelowna.) Results of these

291 comparisons are comparable to those of the Trinidad Head site, although this site shows larger

292 deviations in the upper portion of the profiles between CMAQ and the observed data. Results of

293 comparisons at other west coast sites (not shown) demonstrate similar behavior, with CMAQ

294 generally underestimating $\mathrm{O}_{3}$ near the surface and in the lower and mid troposphere, with the

295 greatest discrepancies in winter and the least in summer. From these profiles it appears that the

$296 \mathrm{O}_{3}$ boundary concentration tracer, as a surrogate for the GEMS data, has considerably

297 underestimated the inflow $\mathrm{O}_{3}$ to the west coast of North America in the lower troposphere,

298 especially during the winter and spring. It is not surprising that the GEMS data should better

299 reflect the observed $\mathrm{O}_{3}$ profile in the upper levels as compared to levels closer to the surface.

300 The GEMS re-analyses have made extensive use of data assimilation for $\mathrm{O}_{3}$ based on satellite

301 retrievals. These derived measurements are most accurate for the stratospheric $\mathrm{O}_{3}$ burden and

302 become more uncertain in the lower portions of the profile. In the lower levels, the GEMS data

303 are more reflective of the results of the MOZART-3 model simulations which appear to have

304 systematically underestimated tropospheric $\mathrm{O}_{3}$ in the northeast Pacific region, and generated a

305 low bias in the specified inflow concentrations for North America, possibly due to emissions

306 uncertainties and an overestimation of dry deposition. 
A distinct advantage of the data assimilation aspect of the GEMS re-analysis is that real-time

308 events, such as large forest fires or dust storms, are seen by satellite sensors and can be

309 incorporated in the model simulation. Figure 9 shows the vertical profiles of primary organic

310 particulate matter $(\mathrm{OM})$ along each boundary of the CMAQ North American domain averaged

311 over the period of 21-30 June 2006 from the GEMS database. One can readily see the strong

312 impact of a large wildfire occurring at the time in the Canadian boreal forest. The impact on

313 surface layer CMAQ estimates of primary organic particulate matter is seen in Figure 10 in

314 which the 01 UTC concentrations are presented for 30 June 2006. The effects of the wildfires

315 north of the CMAQ domain are evident as the boundary concentrations have been advected into

316 the northern portion of CMAQ's computational domain. Satellite measurements confirm the

317 elevated aerosol loadings in this area from the wildfires.

\subsection{CHIMERE Model - North America application}

320 The sensitivity of concentrations simulated by a regional model to chemical boundary 321 conditions was tested by IPSL-France using the CHIMERE model (Bessagnet et al., 2004), by

322 using in separate simulations the GEMS boundary conditions provided to AQMEII (Simulation

323 A) and the boundary conditions typically used in CHIMERE studies, as provided by monthly

324 climatologies of the LMDzINCA global model (Hauglustaine et al., 2004) for gas-phase species

325 and the GOCART model for aerosol species (Ginoux et al., 2001). For this simulation (B),

326 carried out in exactly the same setting as for Simulation A for other model parameters, boundary

327 conditions are constant within each month but vary along model boundaries. It must be noted

328 that CHIMERE only simulates concentrations within the lower atmosphere: it has a top boundary

329 at $500 \mathrm{hPa}$. Concentrations within the modeling domain are thus sensitive to both lateral and top

330 boundary concentrations.

331 The mean $\mathrm{O}_{3}$ surface concentration differences between Simulations B and A have been

332 calculated for each season (Winter $=$ DJF, Spring=MAM, Summer=JJA, Fall=SON) and are

333 represented in Figure 11. The sensitivity to $\mathrm{O}_{3}$ boundary concentrations differs from one season

334 to another. In winter and spring, strong winds and vertical mixing induce a larger sensitivity to

335 boundary concentrations than in summer and fall. For instance, in winter, seasonal mean

336 concentration differences between the two simulations in the center of the domain and those near

337 the boundaries vary by a factor of two or so. In contrast, in summer and fall the concentration 
differences vary by more than a factor of 5 between the center of the domain and the regions near the boundaries, indicating that boundary conditions have a relatively smaller impact on the inner portions of the domain compared to winter and spring. However, in all seasons studied, the impact of boundary conditions extends inland far from the boundaries. The Central-East U.S. shows the smallest influence from the boundary conditions.

343 Note also that the difference between mean LMDzINCA-driven and MOZART-driven

344 simulations remains positive across the domain, because the LMDzINCA $\mathrm{O}_{3}$ boundary

345 conditions are higher than the MOZART ones. This difference is largest in the winter season, and reaches about $15 \mathrm{ppb}$, while in summer it reaches $10 \mathrm{ppb}$. The magnitude of these differences in seasonal mean concentrations caused by different boundary conditions is comparable to those shown in Hogrefe et al. (2011; see figure 11 therein).

\subsection{CHIMERE Model - Europe application}

The CHIMERE model has also been applied over Europe using the TNO emissions inventory at a $0.25^{\circ}$ horizontal resolution by INERIS-France. As in the North American case, the model domain extends vertically to $500 \mathrm{hPa}$. To assess the impact of the temporal resolution of the boundary concentrations (BCs) on air quality modeled in the regional domain, the whole year 2006 has been run twice with 3-hourly GEMS BCs for both gaseous species and aerosols (3HR), and with a monthly climatology derived from the same dataset (gas and aerosols as well; CST). In the CST run, for a given time in a month, the model is driven with constant BCs; no interpolation is performed between two consecutive months.

In Figure 12 we display the average difference between the simulations with 3-hourly BCs and the monthly climatology for $\mathrm{O}_{3}$. With both sets of $\mathrm{BCs}$ derived from the same global simulations, these plots would exhibit a null geographical variability if the regional model behaved as a linear operator. Since that is obviously not the case, these plots reflect the combined impact of (1) the non-linearity of the regional model together with (2) the skewness of the $\mathrm{O}_{3}$ distribution at the boundaries. For instance, the difference is consistently negative at the southern boundary showing that the mean BCs (used in the CST run) lead to an overestimation of $\mathrm{O}_{3}$ compared to the $3 \mathrm{HR}$ BCs. On the western and northern parts of the domain, the situation is less straightforward. In summer (JJA), climatological BCs lead to an overestimation of $\mathrm{O}_{3}$, but in spring and fall they yield an underestimation compared to time-varying fields. It is likely that 
stratospheric intrusions into the troposphere captured in the GEMS re-analysis (which may have an impact in the CHIMERE model down to the surface by means of vertical mixing) play an important role on these patterns. As isolated, yet very concentrated, layers of $\mathrm{O}_{3}$, these events have a larger impact on the average than on the median concentrations. Depending on their geographical and seasonal variability they could thus be responsible for the patterns observed in

374 Figure 12.

375 Figure 13 shows the difference of standard deviation between the 3HR and CST simulation results for both $\mathrm{O}_{3}$ and PM10 concentrations. Using the 3HR fields at the boundary has a noticeable impact on the outskirts of the model domain. Since Europe is mainly affected by sporadic and large dust outbreaks from the Sahara, the southern boundary displays higher variability with $3 \mathrm{HR}$ BCs. The eastern part of the domain includes a fire emission zone in Russia, which leads to higher standard deviations in this region. Since sea salt BCs have been removed in the GEMS dataset there are no specific patterns observed in the western and northern parts of the domain. Table 3 shows the global standard deviation of daily mean concentrations of $\mathrm{O}_{3}, \mathrm{NO}_{2}$, and PM10 for all European air quality monitoring stations taken from the AIRBASE dataset (all available stations). For short-lived species like $\mathrm{NO}_{2}$, the time-varying BCs have a negligible impact. However, for both $\mathrm{O}_{3}$ and PM10, using the $3 \mathrm{HR}$ fields at the boundaries contributes to obtaining a slightly larger variability that is more in agreement with the observations for $\mathrm{O}_{3}$ and $\mathrm{NO}_{2}$. The time variability is impaired for PM10 showing that the predictability of dust events (intensity and occurrence) remains difficult as shown by Menut et al. (2009). If dust models can provide a better measure of variability on seasonal or monthly bases, these models could better predict dust concentrations over Europe on a daily basis. It should be noted that the estimates provided by this comparison at the station locations overly weight the

392 center of the domain, where stations are by far more numerous and the impact of BCs less 393 noticeable.

394 Recently Pfister et al. (2011) conducted similar sensitivity experiments with the WRF-Chem 395 model in which boundary concentrations for North American inflow were derived from the MOZART-4 global chemical transport model using 3-hourly varying data as well as an experiment using boundary data averaged over their simulation period (14-30 June 2008; during ARCTAS-CARB field experiments). Their results focused on inflow to California during that period, and much like the results presented here, the variability in boundary concentrations was 
400 better captured with the higher temporal resolution. One difference that was noted was in the 401 mean $\mathrm{O}_{3}$ concentrations at the boundaries, where Pfister et al. (2011) reported the same mean $\mathrm{O}_{3}$

402 values irrespective of the temporal averaging at the boundaries, while the current study noted 403 differences in the means based on the temporal averaging. This discrepancy in the findings is 404 likely due to the longer simulation period used here (one year) compared to the 17-day 405 simulation period in the Pfister study. The longer simulation allowed for additional anomalous 406 events, such as stratospheric intrusions of $\mathrm{O}_{3}$ into the lower troposphere, to affect the average in 407 non-linear fashion.

\subsection{CMAQ Model - Europe application}

410 The CMAQ model was applied over the European domain for the year 2006 using the input 411 datasets prescribed for AQMEII (including the GEMS boundary concentrations) by the 412 University of Hertfordshire-UK. An evaluation of the CMAQ calculations, for the continental413 scale domains in North America and Europe, is given in Appel et al. (2011; this issue). To 414 examine the impacts of the boundary concentrations on the model results, an additional 415 simulation was performed for 2006 using boundary concentrations provided by the global 416 chemical transport model GEOS-Chem, version 8-03-01 (see http://wiki.seas.harvard.edu/geos417 chem/index.php/Main Page). The GEOS-Chem model was run at a $2^{\circ} \times 2.5^{\circ}$ horizontal 418 resolution with 47 hybrid pressure-sigma vertical levels. The model was driven by assimilated 419 meteorological data from the Goddard Earth Observing System (GEOS-5) at the NASA Global 420 Modeling and Assimilation Office (GMAO). We used the chemistry mechanism $\mathrm{NO}_{\mathrm{x}}-\mathrm{O}_{\mathrm{x}^{-}}$ 421 hydrocarbon-aerosol to simulate $\mathrm{O}_{3}$ and aerosols (Jacob, 2000; Bey et al., 2001). The aerosol 422 components included sulfate, nitrate, ammonium, black carbon, organics, mineral dust, and sea 423 salt (see Park et al., 2004; Hu et al., 2007). The emission inventories were separated into four 424 source categories: anthropogenic, biomass, biofuel, and biogenic. Sources of mineral dust and 425 sea salt are dealt with separately. The anthropogenic emissions were obtained from the Global 426 Emissions Inventory Activity (GEIA) dataset. Biomass burning and biofuel-use emissions were 427 derived from Duncan et al. (2007). Biogenic emissions included isoprene, methyl butenol, 428 acetone, and alkene.

429 As in Section 4.1, we focus on the adequacy of the boundary concentrations data for setting 430 the inflow of $\mathrm{O}_{3}$ into the modeling domain. Figure 14 presents the observed and modeled 
431 vertical distributions of $\mathrm{O}_{3}$ at Lerwick, Shetland Mainland, UK, for the year 2006. The Lerwick 432 Observatory is situated in a remote location representative of background (inflow) atmospheric 433 concentrations. The time-height evolution of $\mathrm{O}_{3}$ in Figure 14a was compiled from measurements 434 by a UK Met Office ozonesonde of the Electrochemical Concentration Cell (ECC) type (Komhyr 435 et al., 1995). The two model calculations agree fairly well with the observations at altitudes 436 above 6-8 km (i.e., in the upper troposphere/lower stratosphere). While the GEMS re-analysis 437 included the assimilation of $\mathrm{O}_{3}$ data from satellite observations, the GEOS-Chem simulation 438 included stratospheric $\mathrm{O}_{3}$ chemistry based on a climatological representation of species sources 439 and sinks. Both techniques appeared to work well in reproducing the $\mathrm{O}_{3}$ profile at the higher 440 altitudes. Interestingly, the agreement degrades in the lower troposphere when using the GEMS 441 boundary concentrations, while it remains fair when using those provided by GEOS-Chem. The 442 difference between the observed $\mathrm{O}_{3}$ concentrations and those of the simulation using the GEMS 443 boundary concentrations is most dramatic for the first four months of 2006, with low biases as 444 large as $20 \mathrm{ppb}$.

445 Similar findings can be observed in Figure 15, where the observed and modeled ground-level $446 \mathrm{O}_{3}$ concentrations at Mace Head, Republic of Ireland, are shown. The location of the monitoring 447 station on the Atlantic Coast makes it a representative site for background concentrations of 448 substances in the atmosphere. The $\mathrm{O}_{3}$ concentration at the site, simulated using the GEMS 449 boundary concentrations, appears to be biased low for the first four months of 2006. Afterwards, 450 the two model calculations give comparable results. This highlights the importance of boundary 451 concentrations in setting the baseline concentrations in the modeling domain.

\subsection{Summary and Conclusions}

The AQMEII project on regional-scale air quality model system evaluation and intercomparison has proposed the use of a common set of boundary concentrations to be specified to the regional modelers for all to use in an effort to minimize differences across the models from this particular aspect of the modeling protocol. The GEMS re-analysis air quality dataset has been provided for this purpose from the ECMWF for the AQMEII focus year of 2006. The re-

460 analysis is produced by assimilating satellite observations of select chemical and aerosol species 461 into a coupled model system, which consists of ECMWF's IFS and the MOZART-3 CTM. The 
462 resulting dataset provides spatially- and temporally-resolved information on concentrations of 463 most of the key transported species of interest to the AQMEII regional modelers for use in their 464 modeling systems. Each regional modeling group then must cast these data into forms directly 465 usable by their particular model. This processing may include further spatial and temporal 466 interpolations as well as chemical speciation of the trace gases and aerosols for the particular 467 chemical and aerosol mechanisms used by the model.

468 In this study we found that specification of $\mathrm{O}_{3}$ profiles from the GEMS dataset at the 469 boundaries of the North American and European modeling domains for the 2006 simulations 470 offered good agreement in the upper troposphere and lower stratosphere with an independent set 471 of observations from ozonesondes. For the North American domain, the $\mathrm{O}_{3}$ boundary 472 concentrations throughout 2006 were underestimated in the GEMS dataset in the lower to mid 473 troposphere, with greater biases in winter and spring and lower biases in summer. In the 474 European simulations the GEMS dataset yielded $\mathrm{O}_{3}$ boundary concentrations that were 475 consistent with ozonesonde observations except for the first quarter of 2006 when the lower tropospheric $\mathrm{O}_{3}$ values were biased low by as much as $20 \mathrm{ppb} . \mathrm{SO}_{2}$ concentrations in the GEMS

478 in the global modeling. AQMEII modelers were cautioned regarding their use for continental 479 boundary concentrations. For particulate matter we found that organic carbon from large fires 480 was well detected by the GEMS data assimilation system, but that concentrations could be 481 overestimated near the surface due to lack of a plume rise mechanism and eight-day temporal 482 averaging of fire emissions. Sea salt was greatly overestimated near the boundaries of the North 483 American domain, although the bias was less over the North Atlantic near the borders of the 484 European domain. The GEMS dataset did not provide estimates of particulate sulfate or nitrate. 485 Specification of boundary concentrations is a required element in modeling with limited-area 486 air quality models, such as regional- to continental-scale CTMs. The limited area models are 487 typically quite sensitive to these specified concentrations, especially in areas of limited internal 488 forcing by emissions and chemistry within the model's computational domain. Sensitivity 489 simulations performed with the CHIMERE model emphasize that the impact of $\mathrm{O}_{3}$ boundary 490 concentrations can extend far into the model domain beyond the boundaries. These studies also 491 show that boundary concentrations derived from monthly $\mathrm{O}_{3}$ climatologies can deviate 492 substantially from more temporally-resolved concentrations. The tropospheric impacts of 
493 stratospheric $\mathrm{O}_{3}$ intrusion events, for example, can be greatly damped or eliminated by monthly 494 averages.

495 Long-duration simulations, such as the full-year simulations performed within the AQMEII 496 project, require boundary concentrations that reflect not only day-to-day variations but also 497 seasonal and inter-annual changes in the global environment. Use of global CTMs to provide 498 these boundary concentrations is a logical and convenient mechanism for their specification. It 499 should be noted, however, as seen in these AQMEII model results, as well as the results 500 presented in Hogrefe et al. (2011), that the global models may contain errors or biases in their 501 simulated results that can then propagate into the regional models through the boundaries and 502 affect the results within the model domain. The use of data assimilation in the global models can 503 help minimize these errors, but cannot eradicate them. The assimilated satellite observations 504 provide mainly vertically integrated column values, which makes it more difficult for the 505 assimilating model to obtain realistic concentration profiles close to the surface. Examining 506 several sources of boundary concentrations, such as alternate global CTMs, may provide useful 507 information to modelers on ranges of boundary concentrations to consider. With the tightening 508 of air quality standards and the imposition of emissions control programs, air pollution levels 509 have generally been declining in many nations, leading to the need to better quantify background 510 pollution as an "irreducible" portion of the local pollutant burden. Therefore the process of 511 specifying boundary concentrations for limited area models is an important issue and must be

512 performed with careful scrutiny to assure the best possible outcome from regional-scale model 513 simulations.

\section{Acknowledgements}

517 In addition to the data sources and organizations acknowledged in the Foreword to this 518 AQMEII Special Issue, we would like to note that the Mace $\mathrm{Head}_{3}$ data were obtained from 519 the Defra UK Air Information Resource (UK AIR, http://uk-air.defra.gov.uk). Participation in 520 this AQMEII study by IPSL and INERIS was supported by the Institut National des Sciences de 521 l'Univers in France through the AQMEII.fr project, and the SALUT'AIR program funded by 522 PRIMEQUAL. A special note of appreciation is extended to the staff and collaborators in the 523 GEMS project within the European Centre for Medium-Range Weather Forecasting (ECMWF) 
524 and other participating organizations for making possible the use of GEMS air quality re-analysis 525 data in the AQMEII project, and for helping process and explain the data details. Thanks are 526 extended to Angela Benedetti, Johannes Kaiser, Jean-Jacques Morcrette, and Adrian Simmons 527 (ECMWF); Martin Schultz (FZ-Jülich); Vincent-Henri Peuch (Meteo-France); Darius Ceburnis 528 (National University of Ireland); and Chris Nolte (U.S. EPA).

529 The views expressed here are those of the authors and do not necessarily reflect the views 530 and policies of the U.S. Environmental Protection Agency or any other organization participating 531 in the AQMEII project. This manuscript has been subjected to U.S. EPA review and approved 532 for publication.

533 


\section{References}

Appel K.W., C. Chemel, S.J. Roselle, X.V. Francis, T. Pierce, S.T. Rao, R.S. Sokhi, and S.

Galmarini, 2011. Examination of the Community Multiscale Air Quality (CMAQ) model performance for North America and Europe for the AQMEII project. submitted to Atmospheric Environment (this issue).

Benedetti, A., J.-J. Morcrette, O. Boucher, et al., 2009. Aerosol analysis and forecast in the European Centre for Medium-Range Weather Forecasts Integrated Forecast System: 2. Data assimilation. Journal of Geophysical Research, 114, D13205, doi:10.1029/2008JD011115.

Bessagnet, B., A. Hodzic, R. Vautard, M. Beekmann, S. Cheinet, C. Honoré, C. Liousse and L. Rouil, 2004. Aerosol modeling with CHIMERE: preliminary evaluation at the continental scale. Atmospheric Environment, 38, 2803-2817.

Bey I., D.J. Jacob, R.M. Yantosca, J.A. Logan, B. Field, A.M. Fiore, Q. Li, H. Liu, L.J. Mickley, and M. Schultz, 2001. Global modeling of tropospheric chemistry with assimilated meteorology: Model description and evaluation. Journal of Geophysical Research, 106, 23,073-23,096.

Bond, T.C., D.G. Streets, K.F. Yarber, S.M. Nelson, J.-H. Woo, and Z. Klimont, 2004. A technology-based global inventory of black and organic carbon emissions from combustion. Journal of Geophysical Research, 109, D14203, doi:10.1029/2003JD003697.

Bousserez, N., J.-L. Atti'e, V.-H. Peuch, M. Michou, and G. Pfister, 2007. Evaluation of the MOCAGE chemistry and transport model during the ICARTT/ITOP experiment. Journal of Geophysical Research, 112, D10S42, doi:10.1029/2006JD007595.

Dennis, R., T. Fox, M. Fuentes, A. Gilliland, S. Hanna, C. Hogrefe, J. Irwin, S.T. Rao, R. Scheffe, K. Schere, D. Steyn, and A. Venkatram, 2010. A framework for evaluating regionalscale numerical photochemical modeling systems. Environmental Fluid Mechanics, 10, 471489.

Duncan, B.N., J.A. Logan, I. Bey, I.A. Megretskaia, R.M. Yantosca, P.C. Novelli, N.B. Jones, and C.P. Rinsland, 2007. The global budget of CO, 1988-1997: source estimates and validation with a global model. Journal of Geophysical Research, 112, D22301, doi:10.1029/2007JD008459. 
564 Eder, B., D. Kang, S.T. Rao, R. Mathur, S. Yu, T. Otte, K. Schere, R. Wayland, S. Jackson, P. 565 Davidson, J. McQueen, and G. Bridgers, 2010. Using national air quality forecast guidance to develop local air quality index forecasts. Bulletin of the American Meteorological Society, 91, 313-326.

Flemming, J., A. Inness, H. Flentje, V. Huijnen, P. Moinat, M.G. Schultz, and O. Stein, 2009.

Coupling global chemistry transport models to ECMWF's integrated forecast system. Geoscientific Model Development, 2, 253-265.

Flemming, J., A. Inness, L. Jones, H.J. Eskes, V. Huijnen, M.G. Schultz, O. Stein, D. Cariolle,

GEMS, 2010. A Monitoring and Forecasting System for Atmospheric Composition. Final report of the GEMS project. Available from http://www.gmes-atmosphere.eu/documents/reports/. $184 p p$.

Ginoux, P., M. Chin, I. Tegen, J.M. Prospero, B. Holben, O. Dubovik, and S.-J. Lin, 2001. Sources and distributions of dust aerosols simulated with the GOCART model. Journal of Geophysical Research, 106, 20255-20273.

Hauglustaine, D.A., F. Hourdin, L. Jourdain, M.A. Filiberti, S. Walters, J.F. Lamarque, and E.A.

Hogrefe, C., W. Hao, E.E. Zalewsky, J.-Y. Ku, B. Lynn, C. Rosenzweig, M.G. Schultz, S. Rast, Holland, 2004. Interactive chemistry in the Laboratoire de Météorologie Dynamique general circulation model: Description and background tropospheric chemistry evaluation, Journal of Geophysical Research, 109, D04314, doi :10.1029/2003JD003957.

M.J. Newchurch, L. Wang, P.L. Kinney, and G. Sistla, 2011. An analysis of long-term regional-scale ozone simulations over the Northeastern United States: variability and trends. Atmospheric Chemistry and Physics, 11, 567-582, doi:10.5194/acp-11-567-2011.

Hollingsworth, A., R.J. Engelen, A. Benedetti, A. Dethof, J. Flemming, J.W. Kaiser, J.-J. Morcrette, A.J. Simmons, C. Textor, O. Boucher, F. Chevallier, P. Rayner, H. Elbern, H. Eskes, C. Granier, V.-H. Peuch, L. Rouil, M.G. Schultz, 2008. Toward a monitoring and forecasting system for atmospheric composition: The GEMS Project. Bulletin of the American Meteorological Society, 89, 1147-1164. 
594 Honoré, C., L. Rouïl, R. Vautard, M. Beekmann, B. Bessagnet, A. Dufour, C. Elichegaray, J.-M.

595 Flaud, L. Malherbe, F. Meleux, L. Menut, D. Martin, A. Peuch, V.-H. Peuch, and N. Poisson, 2009. PREV'AIR: an operational forecasting and mapping system for air quality in Europe. Bulletin of the American Meteorological Society, 90, 73-83.

Hu, R.-M., R.V. Martin, and T.D. Fairlie, 2007. Global retrieval of columnar aerosol single scattering albedo from space-based observations, Journal of Geophysical Research, 112, D02204, doi:10.1029/2005JD006832.

Huijnen, V., J. Williams, M. van Weele, T. van Noije, M. Krol, F. Dentener, A. Segers, S.

Inness, A., J. Flemming, M. Suttie and L. Jones, 2009. GEMS data assimilation system for

Jacob, D.J., 2000. Heterogeneous chemistry and tropospheric ozone. Atmospheric Environment, 34, 2131-2159.

Kinnison, D.E., G.P. Brasseur, S. Walters, R.R. Garcia, D.R. Marsh, F. Sassi, V.L. Harvey, C.E.

Li, Q., D.J. Jacob, P.I. Palmer, B.N. Duncan, B.D. Field, A.M. Fiore, R.M. Yantosca, D. Parrish, chemically reactive gases. Technical Memorandum No. 587, European Centre for MediumRange Weather Forecasts (ECMWF), Reading, UK.

Randall, L. Emmons, J.F. Lamarque, P. Hess, J.J. Orlando, X. Tie, W. Randel, L.L. Pan, A. Gettelman, C. Granier, T. Diehl, U. Niemeier, and A.J. Simmons, 2007. Sensitivity of chemical tracers to meteorological parameters in the MOZART-3 chemical transport model. Journal of Geophysical Research, 112, D03303, doi:10.1029/2008JD010739.

Komhyr, W.D., R.A. Barnes, G.B. Brothers, J.A. Lathrop, and D.P. Opperman, 1995. Electrochemical Concentration Cell ozonesonde performance evaluation during STOIC 1989. Journal of Geophysical Research, 100, 9231-9244.

P.G. Simmonds, and S. Oltsman, 2002. Transatlantic transport of pollution and its effects on surface ozone in Europe and North America. Journal of Geophysical Research, 107(D13), 4166, doi:10.1029/2001JD001422.

Makar, P.A., W. Gong, C. Mooney, J. Zhang, D. Davignon, M. Samaali, M.D. Moran, H. He, D.W. Tarasick, D. Sills, and J. Chen, 2010. Dynamic adjustment of climatological ozone 
boundary conditions for air-quality forecasts. Atmospheric Chemistry and Physics, 10, 89979015.

McKeen, S., J. Wilczak, G. Grell, I. Djalalova, S. Peckham, E.-Y. Hsie, W. Gong, V. Bouchet, S. Menard, R. Moffet, J. McHenry, J. McQueen, Y. Tang, G. Carmichael, M. Pagowski, A. Chan, T. Dye, G. Frost, P. Lee, and R. Mathur, 2005. Assessment of an ensemble of seven real-time ozone forecasts over eastern North America during the summer of 2004. Journal of Geophysical Research, 110, D21307, doi:10.1029/2005JD005858.

Menut L., I. Chiapello and C. Moulin, 2009. Previsibility of mineral dust concentrations: The CHIMERE-DUST forecast during the first AMMA experiment dry season. Journal of Geophysical Research, 114, D07202, doi:10.1029/2008JD010523.

Morcrette, J.-J., O. Boucher, L. Jones, D. Salmond, P. Bechtold, A. Beljaars, A. Benedetti, A. Bonet, J. W. Kaiser, M. Razinger, M. Schulz, S. Serrar, A. J. Simmons, M. Sofiev, M. Suttie, A. M. Tompkins, and A. Untch, 2009. Aerosol analysis and forecast in the ECMWF Integrated Forecast System. Part I: Forward modeling. Journal of Geophysical Research, 114D, D06206, doi:10.1029/2008JD011235.

Park, R.J., D.J. Jacob, B.D. Field, R.M. Yantosca, and M. Chin, 2004. Natural and transboundary pollution influences on sulfate-nitrate-ammonium aerosols in the United States: implications for policy. Journal of Geophysical Research, 109, D15204, doi:10.1029/2003JD004473.

Pfister, G.G., D. Parrish, H. Worden, L.K. Emmons, D.P. Edwards, C. Wiedinmyer, G.S. Diskin, G. Huey, S.J. Oltmans, V. Thouret, A. Weinheimer, and A. Wisthaler, 2011. Characterizing summertime chemical boundary conditions for airmasses entering the U.S. West Coast. Atmospheric Chemistry and Physics, 11, 1769-1790.

Rabier, F., H. Järvinen, E. Klinker, J.F. Mahfouf, and A.J. Simmons, 2000. The ECMWF operational implementation of four dimensional variational assimilation. Part 1: Experimental results with simplified physics. Quarterly Journal of the Royal Meteorological Society, 126, 1143-1170.

Rao, S.T., S. Galmarini, and K. Puckett, 2011. Air Quality Model Evaluation International Initiative (AQMEII): Advancing state-of-science in regional photochemical modeling and its applications. Bulletin of the American Meteorological Society, 92, 23-30. 
653 Rastigejev, Y., R. Park, M.P. Brenner, and D.J. Jacob, 2010. Resolving intercontinental pollution 654 plumes in global models of atmospheric transport. Journal of Geophysical Research, 115, 655 D02302, doi:10.1029/2009JD012568, 2010

656 Schultz, M.G., T. Pulles, R. Brand, M. van het Bolscher, and S.B. Dalsøren, 2009. A global data 657 set of anthropogenic CO, NOx, and NMVOC emissions for 1960-2000. Available at:

$658 \quad$ http://retro.enes.org/data emissions.shtml.

659 Szopa, S., G. Forêt, L. Menut, and A. Cozic, 2009. Impact of large-scale circulation on European 660 summer surface ozone and consequences for modeling forecast. Atmospheric Environment, $66143,1189-1195$.

662 Tarasick, D.W., et al., 2010. High-resolution tropospheric ozone fields for INTEX and ARCTAS 663 from IONS ozonesondes. Journal of Geophysical Research, 115, D20301, 664 doi:10.1029/2009JD012918.

665 van der Werf, G.R., J.T. Randerson, L. Giglio, G.J. Collatz, P.S. Kasibhatla, and A.F. Arellano 666 Jr., 2006. Interannual variability in global biomass burning emissions from 1997 to 2004.

667 Atmospheric Chemistry and Physics, 6, 3423-3441.

668 Vautard, R., P. Builtjes, P. Thunis, C. Cuvelier, M. Bedogni, B. Bessagnet, C. Honore, N.

669 Moussiopoulos, G. Pirovano, M. Schaap, R. Stern, L. Tarrason, and P. Wind, 2007.

670 Evaluation and inter-comparison of ozone and PM10 simulations by several chemistry

671 transport models over four European cities within the CityDelta project. Atmospheric

672 Environment, 41, 173-188.

673 
674 Table 1. Gas-phase reactive chemical and aerosol species extracted from GEMS data 675

676

\begin{tabular}{|c|c|c|}
\hline \multicolumn{3}{|c|}{ Gas-phase Reactive Chemical Species $^{1}$} \\
\hline $\mathrm{O}_{3}$ (ozone) & $\mathrm{HNO}_{3}$ (nitric acid) & C2H6 (ethane) \\
\hline $\mathrm{CO}$ (carbon monoxide) & $\mathrm{HO}_{2} \mathrm{NO}_{2}$ (peroxynitric acid) & ISOP (isoprene) \\
\hline $\mathrm{CH}_{2} \mathrm{O}$ (formaldehyde) & PAN (peroxy acetyl nitrate) & $\begin{array}{l}\text { TOLUENE } \\
\text { (sum of } \mathrm{C} 7, \mathrm{C} 8, \mathrm{C} 9 \text { aromatics) }\end{array}$ \\
\hline NO (nitrogen oxide) & $\mathrm{CH}_{4}$ (methane) & BIGENE (>C3 alkenes) \\
\hline $\mathrm{NO}_{2}$ (nitrogen dioxide) & $\mathrm{CH}_{3} \mathrm{CHO}$ (acetaldehyde) & BIGALK ( $>\mathrm{C} 3$ alkanes) \\
\hline \multicolumn{3}{|l|}{ Aerosol Species $^{2}$} \\
\hline Sea Salt (0.03-0.5 micrometer) & $\begin{array}{l}\text { Desert Dust } \\
(0.03-0.55 \text { micrometer })\end{array}$ & OM (organic matter) \\
\hline Sea Salt (0.5-5 micrometer) & $\begin{array}{l}\text { Desert Dust } \\
(0.55-0.9 \text { micrometer })\end{array}$ & BC (black carbon) \\
\hline Sea Salt (5-20 micrometer) & $\begin{array}{l}\text { Desert Dust } \\
(0.9-20 \text { micrometer })\end{array}$ & $\mathrm{SO}_{2}$ (sulfur dioxide-gas) ${ }^{3}$ \\
\hline \multicolumn{3}{|l|}{ Other Variables } \\
\hline $\mathrm{T}$ (temperature) ${ }^{4}$ & PS (surface pressure) $)^{5}$ & \\
\hline
\end{tabular}

volume mixing ratios; units: mole mole ${ }^{-1}$

${ }^{2}$ units: $\mu \mathrm{g} \mathrm{m}^{-3}$; size distribution bins are chosen so that roughly 10,20 and 70 percent of the total mass of each aerosol type are in the three successive bins

${ }^{3} \mathrm{SO}_{2}$ here is based on simple assumptions of emissions and prescribed loss; no active chemistry

${ }^{4}$ units: ${ }^{\circ} \mathrm{K}$; used in conversion between molar and mass mixing ratios for gas-phase species

${ }^{5}$ units: $\mathrm{Pa}$; used in conversion of model layer number to atmospheric pressure 
683 Table 2. Boundary Concentration Data Sources Used by AQMEII Participants

\begin{tabular}{|l|l|l|}
\hline AQMEII Participant & Model System & $\begin{array}{l}\text { Source of Boundary } \\
\text { Concentration Data }\end{array}$ \\
\hline $\begin{array}{l}\text { ZAMG - Austrian Weather } \\
\text { Service - AT }\end{array}$ & ALADIN/CAMx & CECILIA model \\
\hline Environment Canada - CA & GEM/AURAMS & $\begin{array}{l}\text { Climatological chemical } \\
\text { boundary concentrations with } \\
\text { dynamic O } \text { adjustments } \\
\text { (Makar et al., 2010) }\end{array}$ \\
\hline Paul Scherrer Institute - CH & WRF/CAMx & GEMS re-analysis \\
\hline $\begin{array}{l}\text { Leibniz Institute for } \\
\text { Tropospheric Research - DE }\end{array}$ & COSMO & GEMS re-analysis \\
\hline HZG Research Centre - DE & CCLM/CMAQ & GEMS re-analysis \\
\hline $\begin{array}{l}\text { University of Aarhus - DK } \\
\text { Barcelona Supercomputing } \\
\text { Centre - ES }\end{array}$ & MM5v3/DEHM & $\begin{array}{l}\text { DEHM hemispheric } \\
\text { simulation }\end{array}$ \\
\hline $\begin{array}{l}\text { Finnish Meteorological } \\
\text { Institute - FI }\end{array}$ & ECMWF/CMALAM & GEMS re-analysis \\
\hline CEREA - FR & POLYPHEMUS & GEMS re-analysis \\
\hline $\begin{array}{l}\text { INERIS/IPSL - FR } \\
\text { Meteorological Service of } \\
\text { Croatia - HR }\end{array}$ & EMEP/HIRLAM-PS & GEMS re-analysis \\
\hline TNO - NL & LOTOS-EUROS & $\begin{array}{l}\text { GEMS re-analysis; } \\
\text { LMDzINCA model }\end{array}$ \\
\hline Kings College London - UK & WRF/CMAQ & EMEP model \\
\hline $\begin{array}{l}\text { University of Hertfordshire - } \\
\text { UK }\end{array}$ & WRF/CMAQ & GEMS re-analysis \\
\hline $\begin{array}{l}\text { Environmental Protection } \\
\text { Agency - US }\end{array}$ & WRF/CMAQ & $\begin{array}{l}\text { GEMS re-analysis; } \\
\text { GEOS-Chem }\end{array}$ \\
\hline Environ Corporation - US & WRF/CAMx & GEMS re-analysis \\
\hline
\end{tabular}


687 Table 3. Standard deviation of daily means at the location of surface air quality monitoring 688 stations for $\mathrm{O}_{3}, \mathrm{NO}_{2}$ and PM10 in the data and in the two CHIMERE model simulations (3HR 689 and CST).

690

691

\begin{tabular}{|l|l|l|l|}
\hline & Obs. data & 3HR & CST \\
\hline $\mathrm{O}_{3}(\mu \mathrm{g} / \mathrm{m} 3)$ & 26.17 & 21.67 & 21.26 \\
\hline $\mathrm{NO}_{2}(\mu \mathrm{g} / \mathrm{m} 3)$ & 16.48 & 13.11 & 13.12 \\
\hline PM10 $(\mu \mathrm{g} / \mathrm{m} 3)$ & 22.75 & 24.11 & 23.93 \\
\hline
\end{tabular}

692

693 


\section{Figure Captions}

Fig 1. Schematic of the components of the GEMS modeling system (figure provided courtesy of M.G. Schultz, FZ-Jülich).

Fig. 2. Timeline of satellite data usage for variables used in the GEMS re-analysis. AQMEII modeling is focused on 2006.

Fig. 3. Domain cut-outs from global GEMS re-analysis grid used for providing boundary concentrations for (a) Europe and (b) North America.

Fig. 4. Time series of May - September average daily maximum 1-h $\mathrm{O}_{3}$ concentrations for observations and two sets of CMAQ simulations. CMAQ/Profile refers to the CMAQ simulations utilizing time-invariant climatological vertical profiles for the specification of boundary conditions while CMAQ/Global refers to the CMAQ simulations utilizing boundary conditions derived from a global chemistry model. The time series represent spatial averages over the location of all $\mathrm{O}_{3}$ monitors in the modeling domain. Further details on these simulations are provided in Hogrefe et al. (2011).

Fig. 5. Locations of IONS-2006 North American ozonesonde launch sites within the CMAQ modeling domain. Shaded area represents the analysis region for inflow air from the western boundary of the domain.

Fig. 6. Mean $\mathrm{O}_{3}$ concentrations for (a) March 2006 and (b) August 2006 for vertical profiles at Trinidad Head, California (US). Observed mean concentrations (with standard deviations) are indicated by gray circles; CMAQ mean concentrations are indicated by open circles; boundarytracer concentrations are indicated by triangles.

Fig. 7. Fractional contribution of the boundary conditions to the simulated mean vertical $\mathrm{O}_{3}$ distributions during March and August 2006 at Trinidad Head.

Fig. 8. Same as Fig. 5, except for Kelowna, British Columbia (Canada).

Fig. 9. Vertical profiles from the GEMS re-analysis database of primary organic particulate matter (OM) along each boundary of the CMAQ model North American domain averaged over the period of 21-30 June 2006.

Fig. 10. CMAQ model-predicted average primary organic aerosol on 30 June 2006 at 01 UTC using GEMS boundary concentrations.

Fig. 11. Mean seasonal distribution for 2006 of the difference of surface $\mathrm{O}_{3}$ concentration between the CHIMERE simulation using the LMDzINCA (gas phase) and GOCART (aerosols) boundary conditions and that using the GEMS boundary conditions. Concentration differences are in ppb. The horizontal resolution of the simulations is $36 \mathrm{~km}$. Each panel corresponds to a seasonal mean. 
Fig 12. Seasonal mean of the bias in modeled $\mathrm{O}_{3}(\mathrm{ppb})$ at the surface in the CHIMERE model: difference between the simulation driven by 3-hourly boundary conditions and the monthly climatology, JFD (January, February, December), MAM (March, April, May), JJA (June, July, August), SON (September, October, November).

Fig. 13. Difference in standard deviation of modeled $\mathrm{O}_{3}$ (left, ppb) and PM10 (right, $\mu \mathrm{g} / \mathrm{m}^{3}$ ) at the surface in the CHIMERE model between the simulation driven by 3-hourly BCs and when a monthly climatology is used at the boundaries.

Fig 14. Vertical distribution of $\mathrm{O}_{3}$ at Lerwick, Shetland Mainland, UK, for the year 2006 as (a) observed, (b) simulated with CMAQ model using the GEMS boundary concentrations, and (c) simulated with CMAQ model using the GEOS-Chem boundary concentrations.

Fig. 15. Time series of observed (black) and CMAQ-simulated (colors) 1-h $\mathrm{O}_{3}$ concentrations at Mace Head, Republic of Ireland, for the year 2006 for (a) the simulation using the GEMS boundary concentrations and (b) that using the GEOS-Chem boundary concentrations. Color variations in simulated time series represents different seasons. 
Figure 1

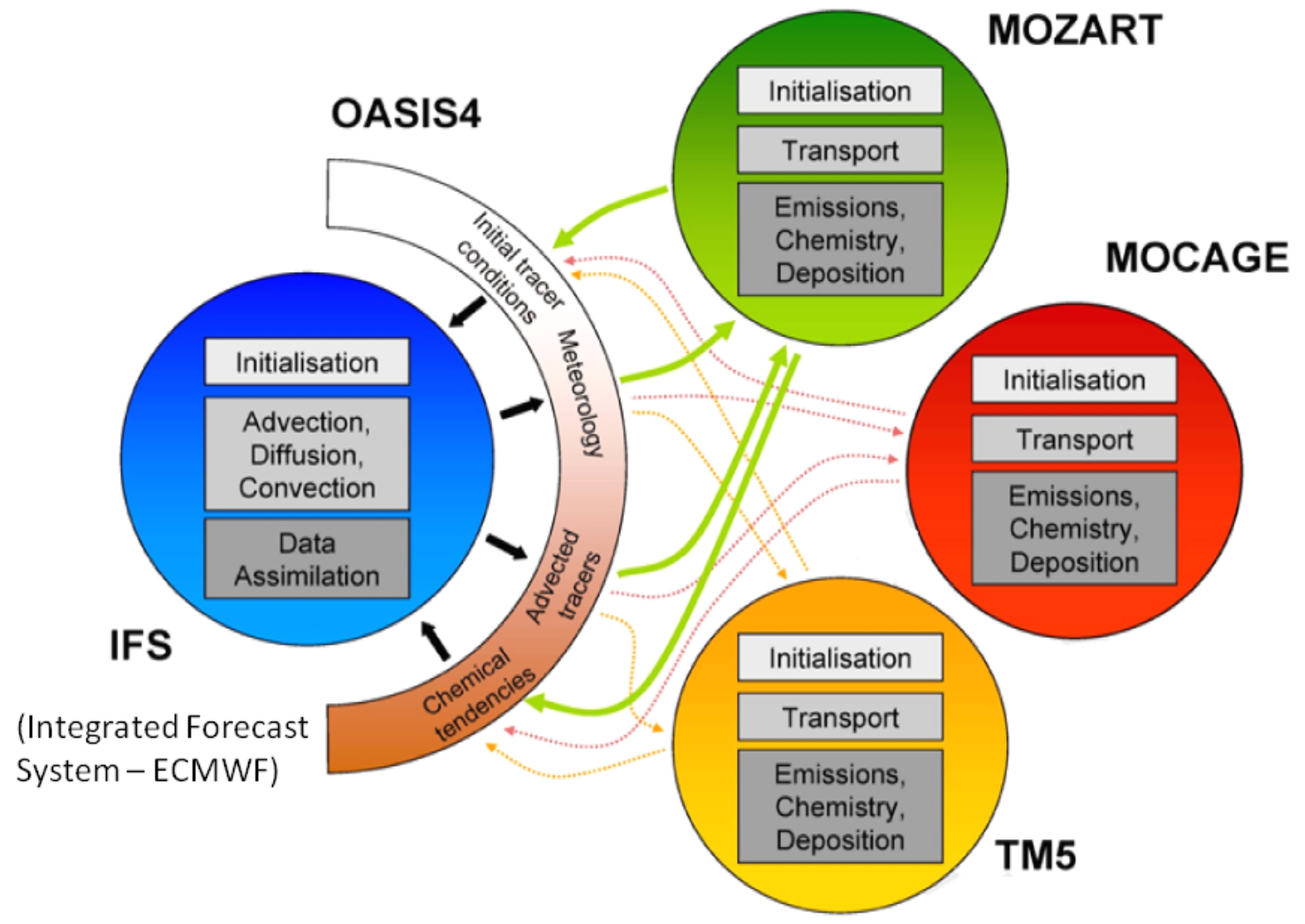


Figure 2

\begin{tabular}{|c|c|c|c|c|}
\hline 2003 & 2004 & 2005 & 2006 & 2007 \\
\hline \multicolumn{5}{|c|}{ AIRS radiances (CO2) } \\
\hline \multicolumn{3}{|c|}{ SCIAMACHY (CH4) } & & \\
\hline \multicolumn{5}{|c|}{ SCIAMACHY (O3) } \\
\hline \multicolumn{5}{|c|}{ SBUV (O3) } \\
\hline \multicolumn{5}{|l|}{ MIPAS (O3) } \\
\hline \multicolumn{5}{|l|}{ GOME (O3) } \\
\hline \multicolumn{5}{|c|}{ MLS (O3) } \\
\hline & & & & OMI (O3) \\
\hline \multicolumn{5}{|c|}{ MOPIT (CO) } \\
\hline \multicolumn{5}{|c|}{ AQUA MODIS (AOD) } \\
\hline & & TERRA MODIS (AOD) & & \\
\hline
\end{tabular}


Figure 3 (a)

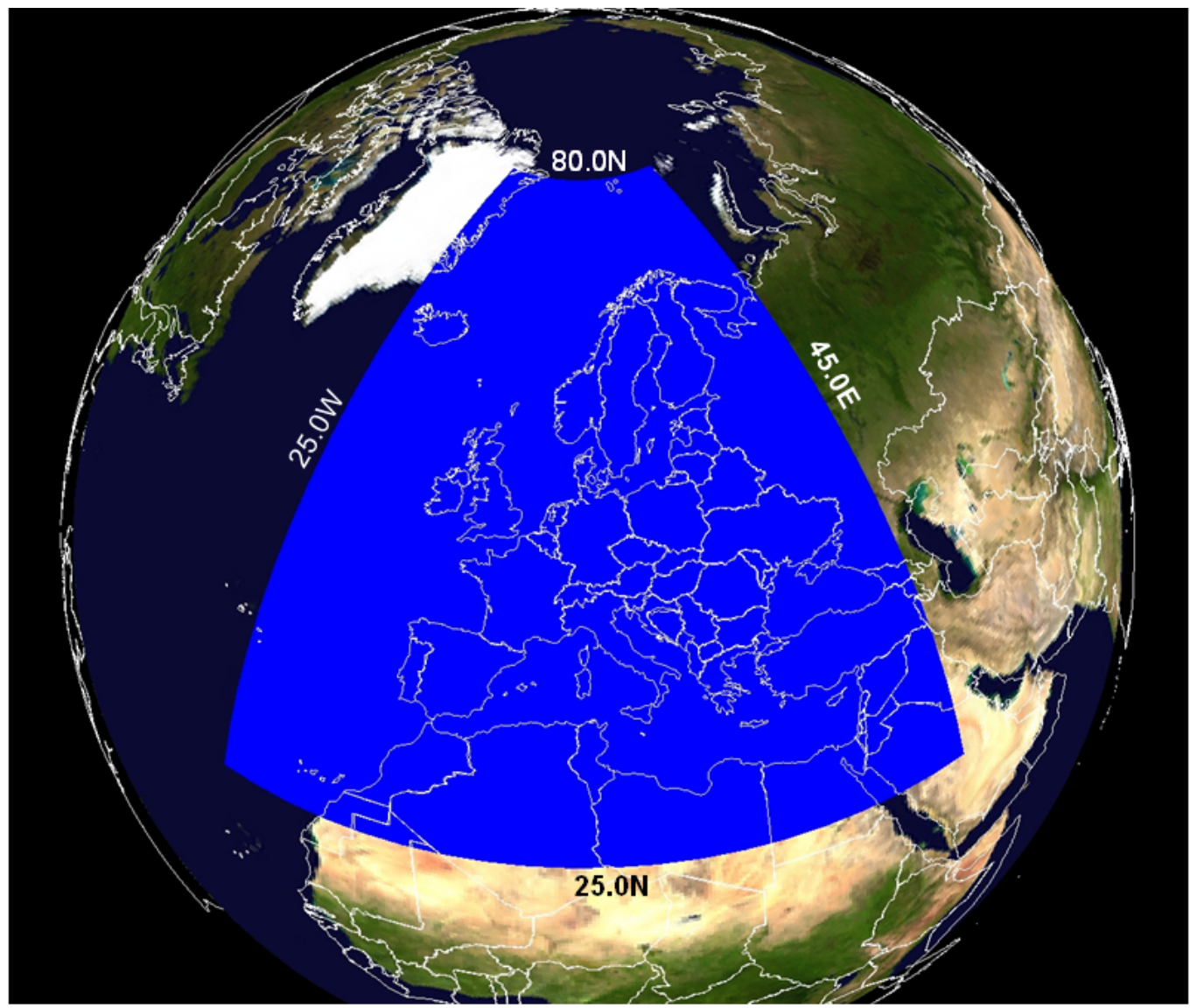


Figure $3 b$

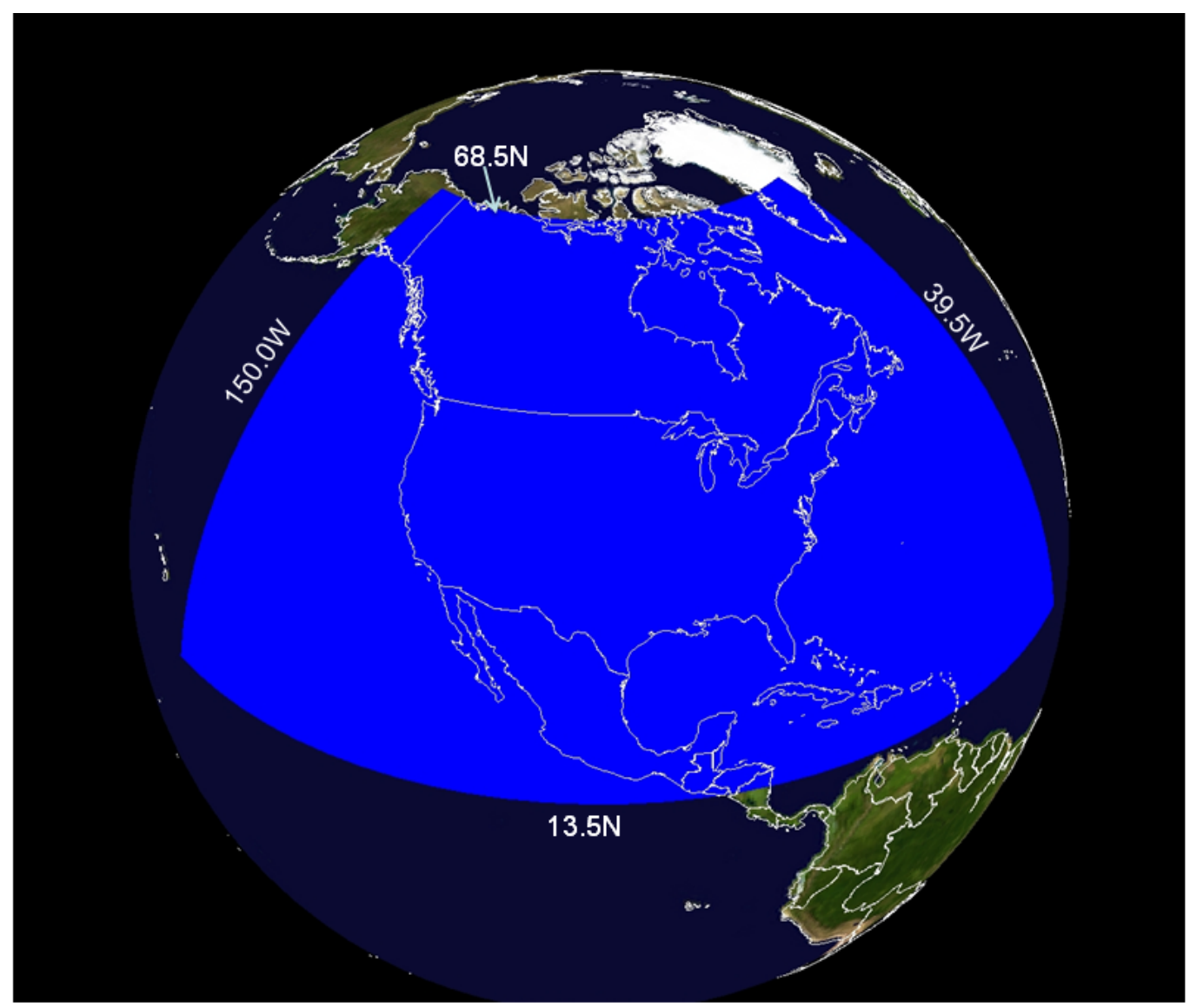


Figure 4.

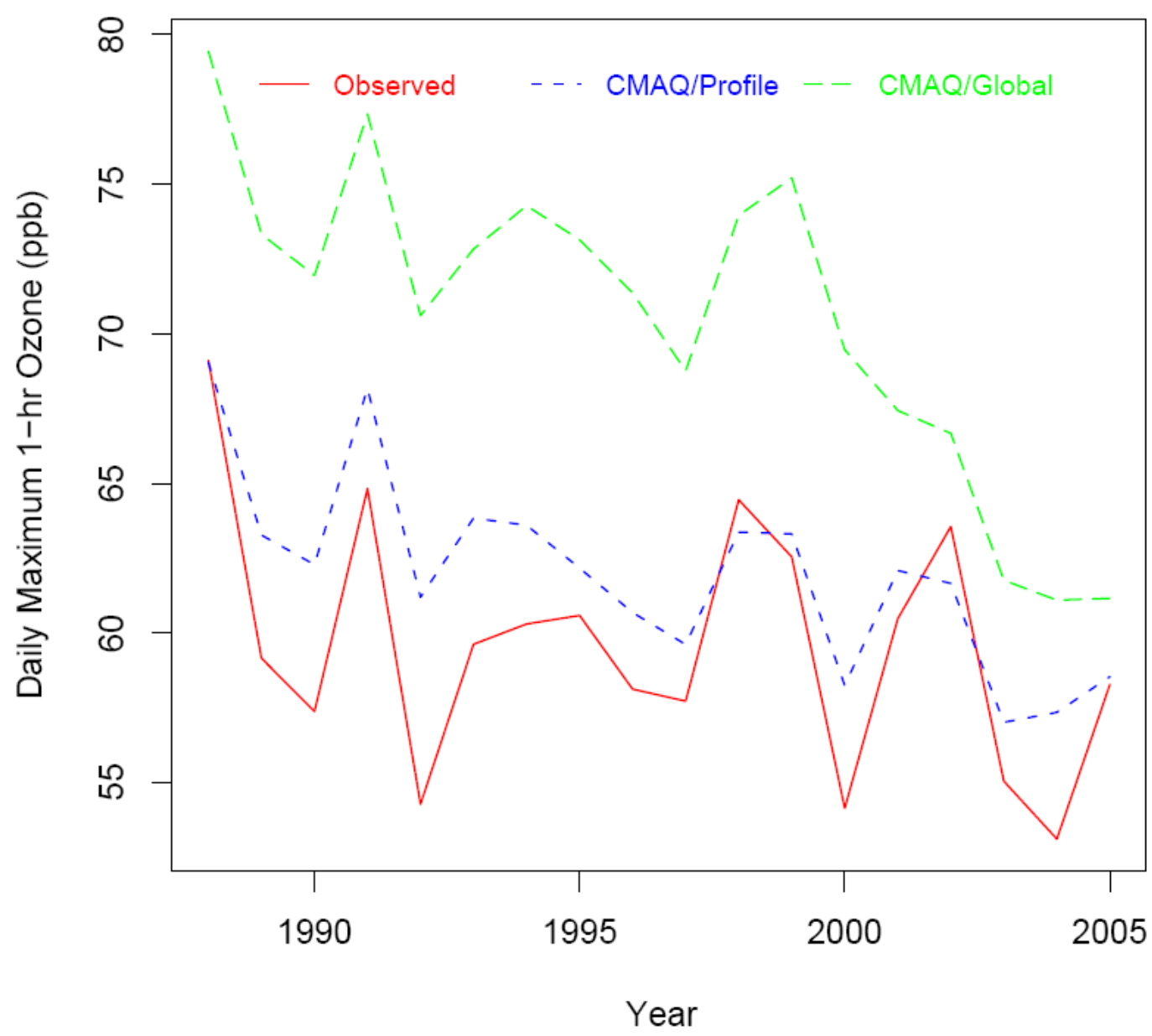


Figure 5

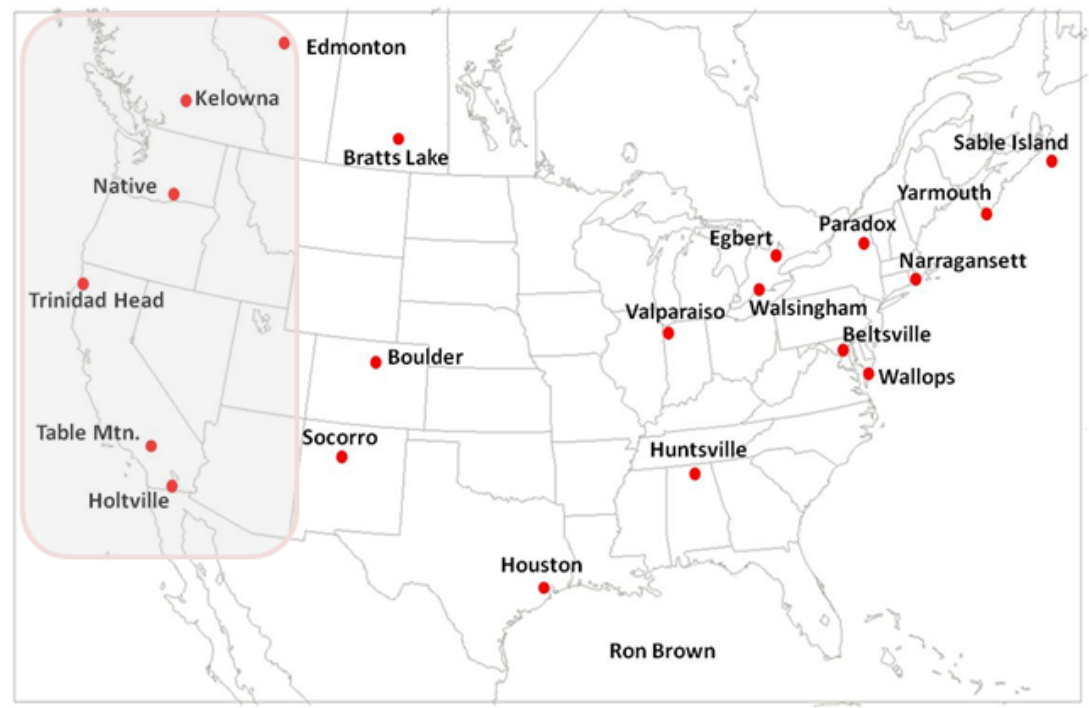


Figure 6a

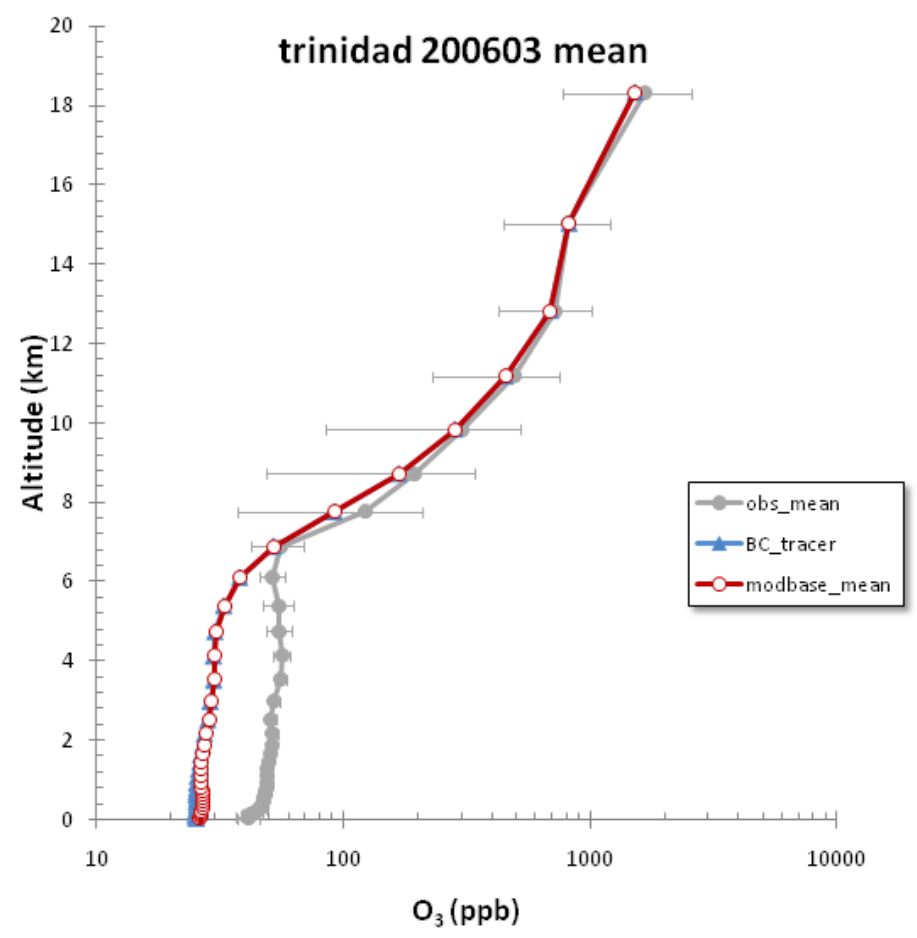


Figure $6 \mathrm{~b}$

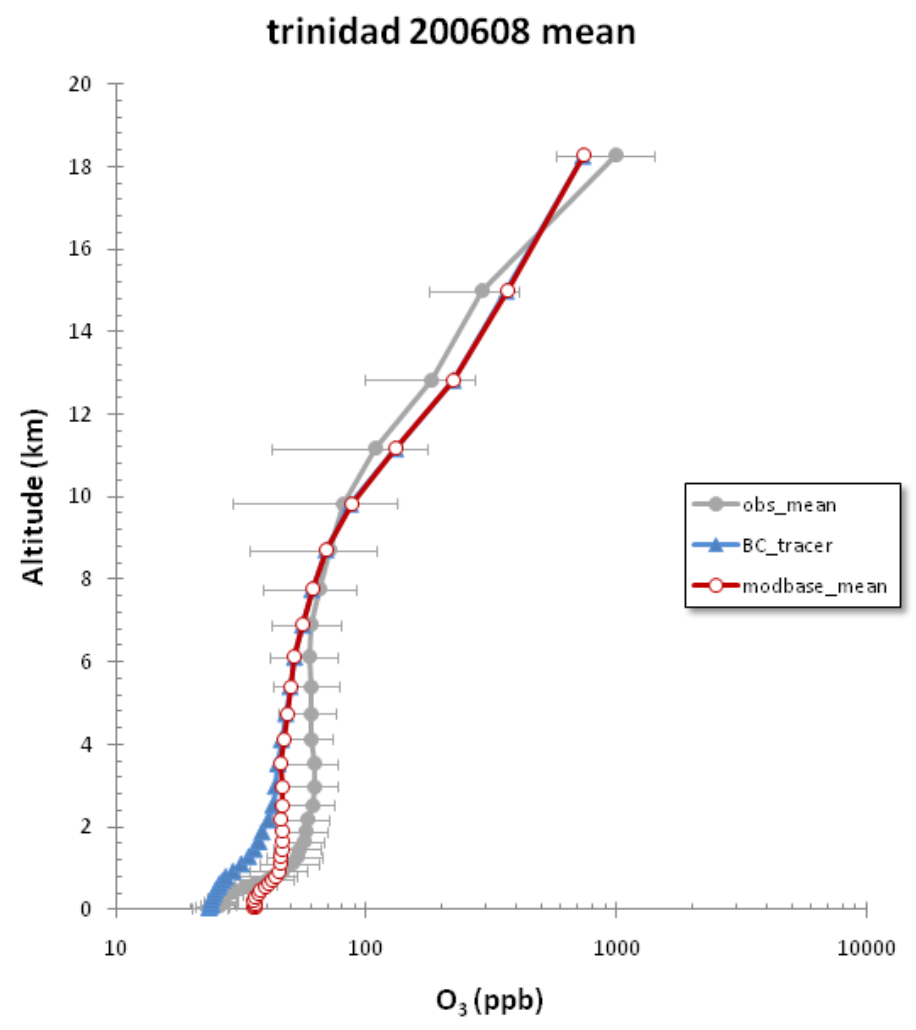


Figure 7

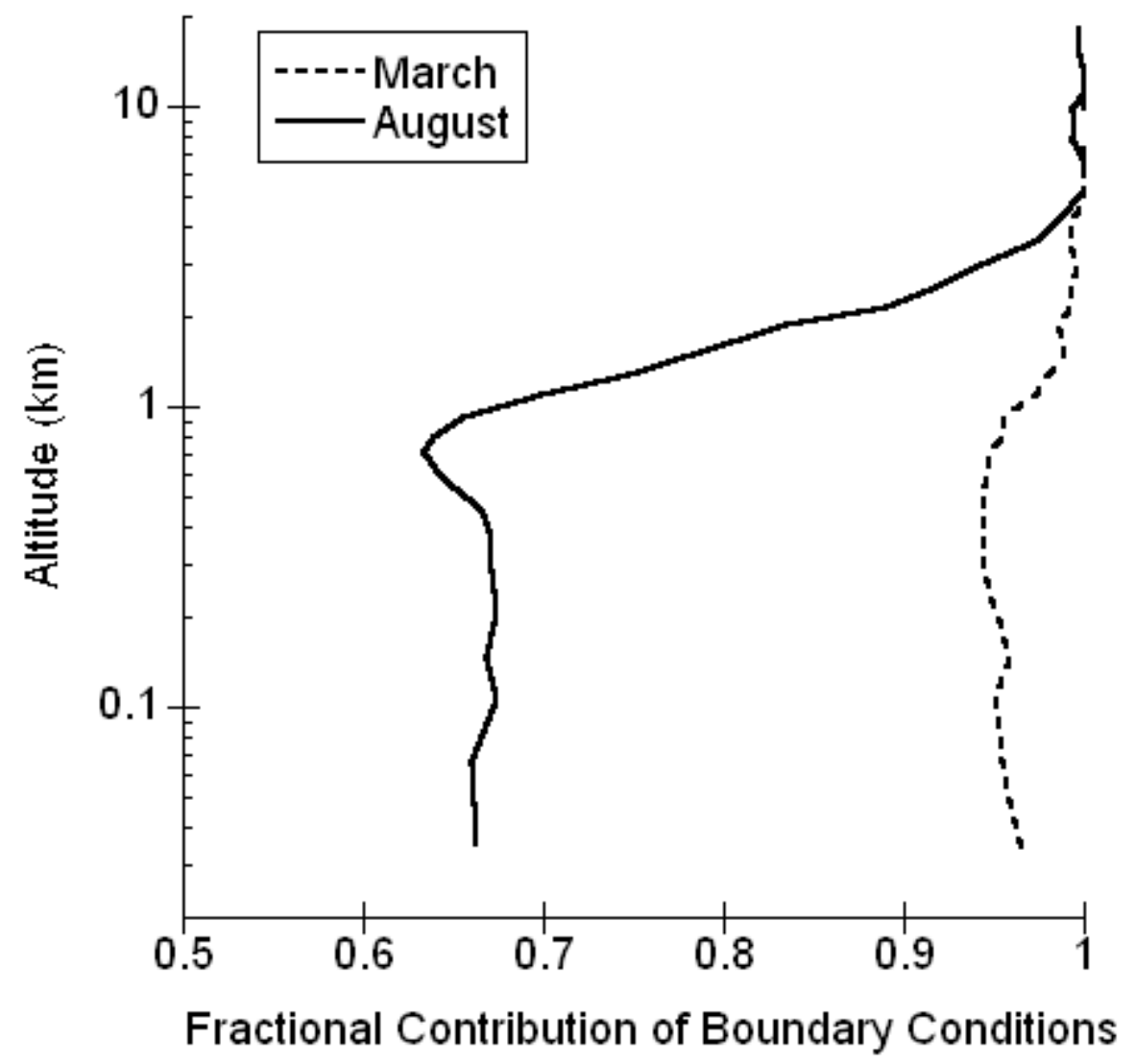


Figure 8a

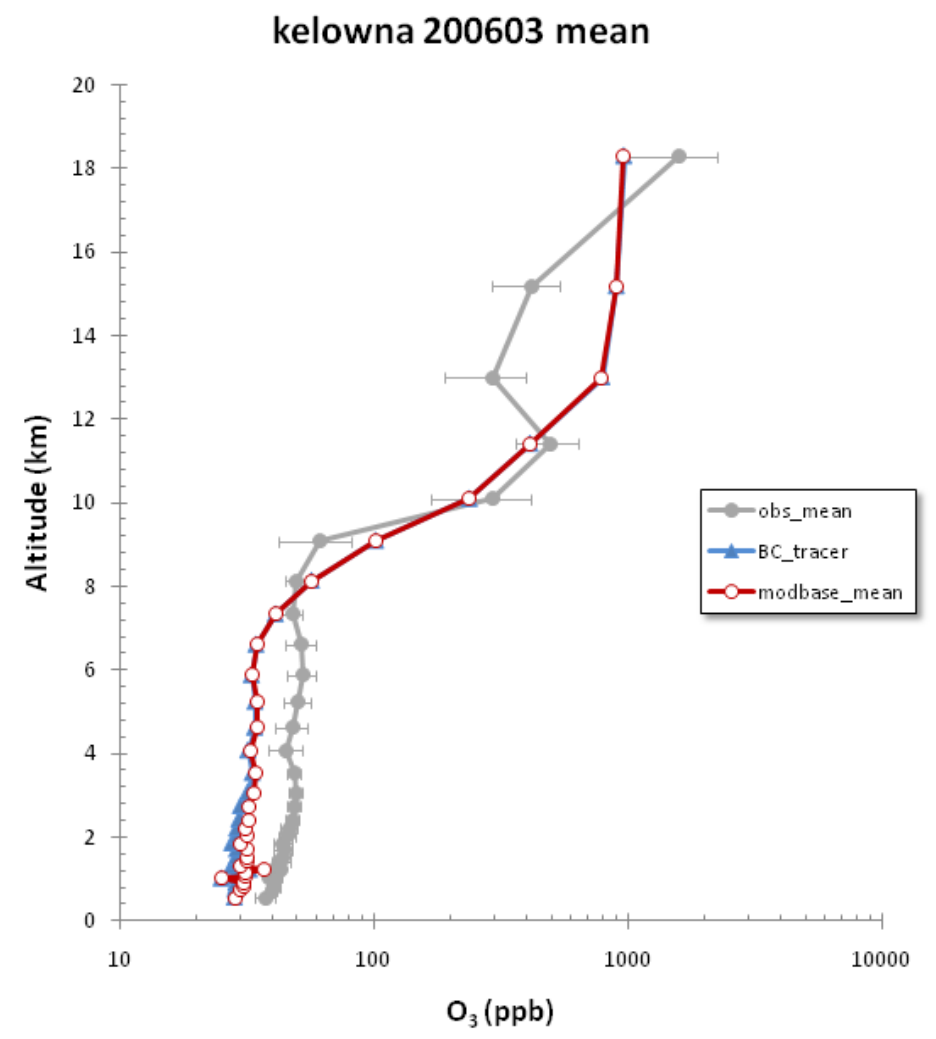


Figure $8 b$

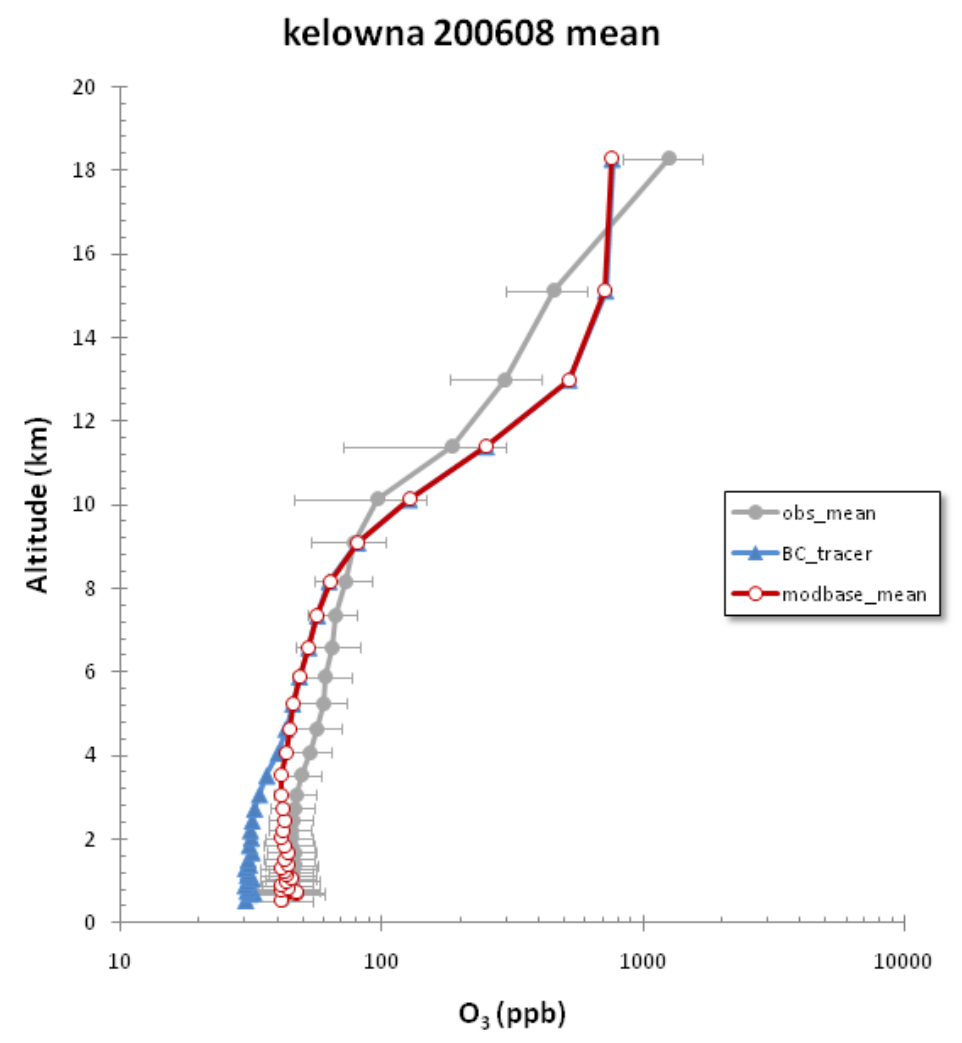


Figure 9

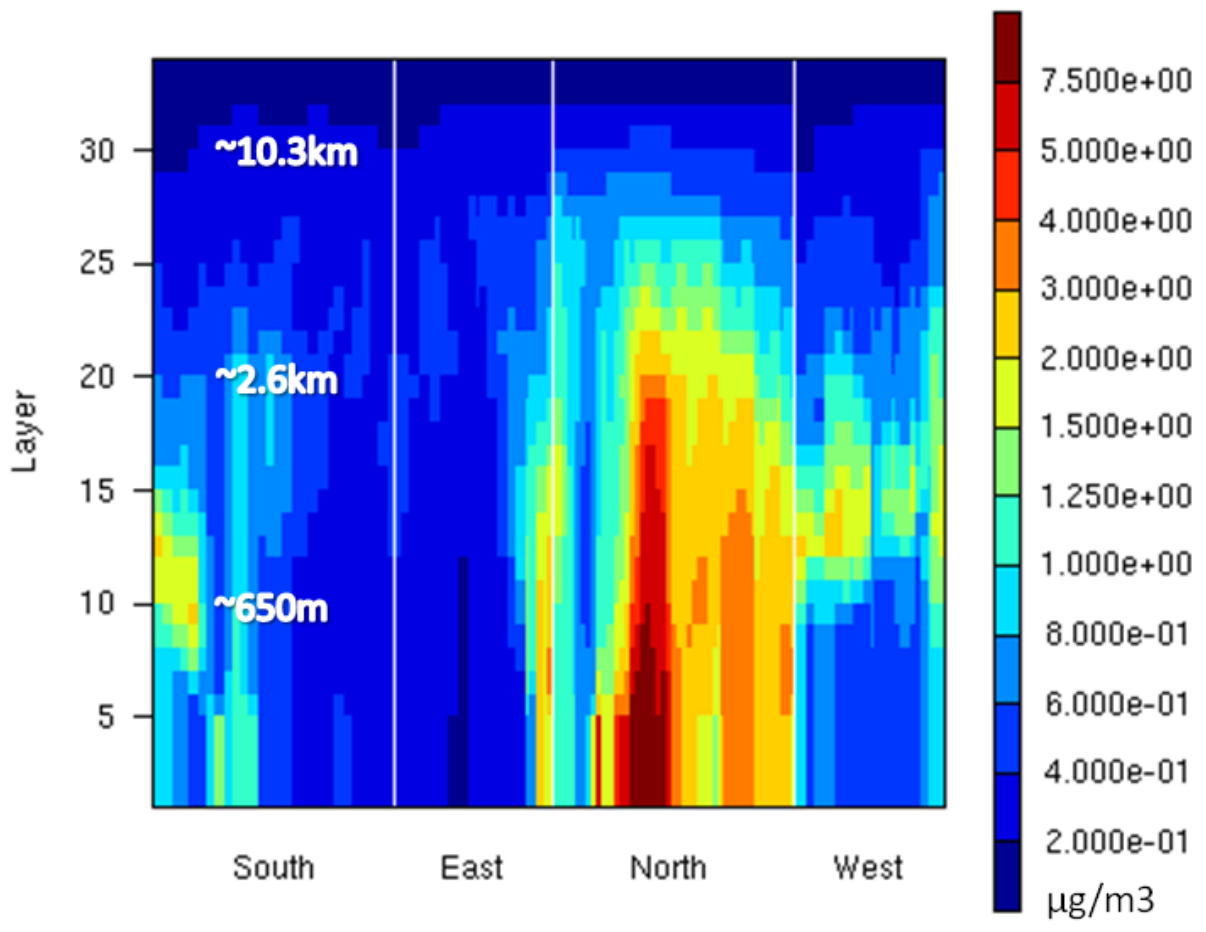


Figure 10

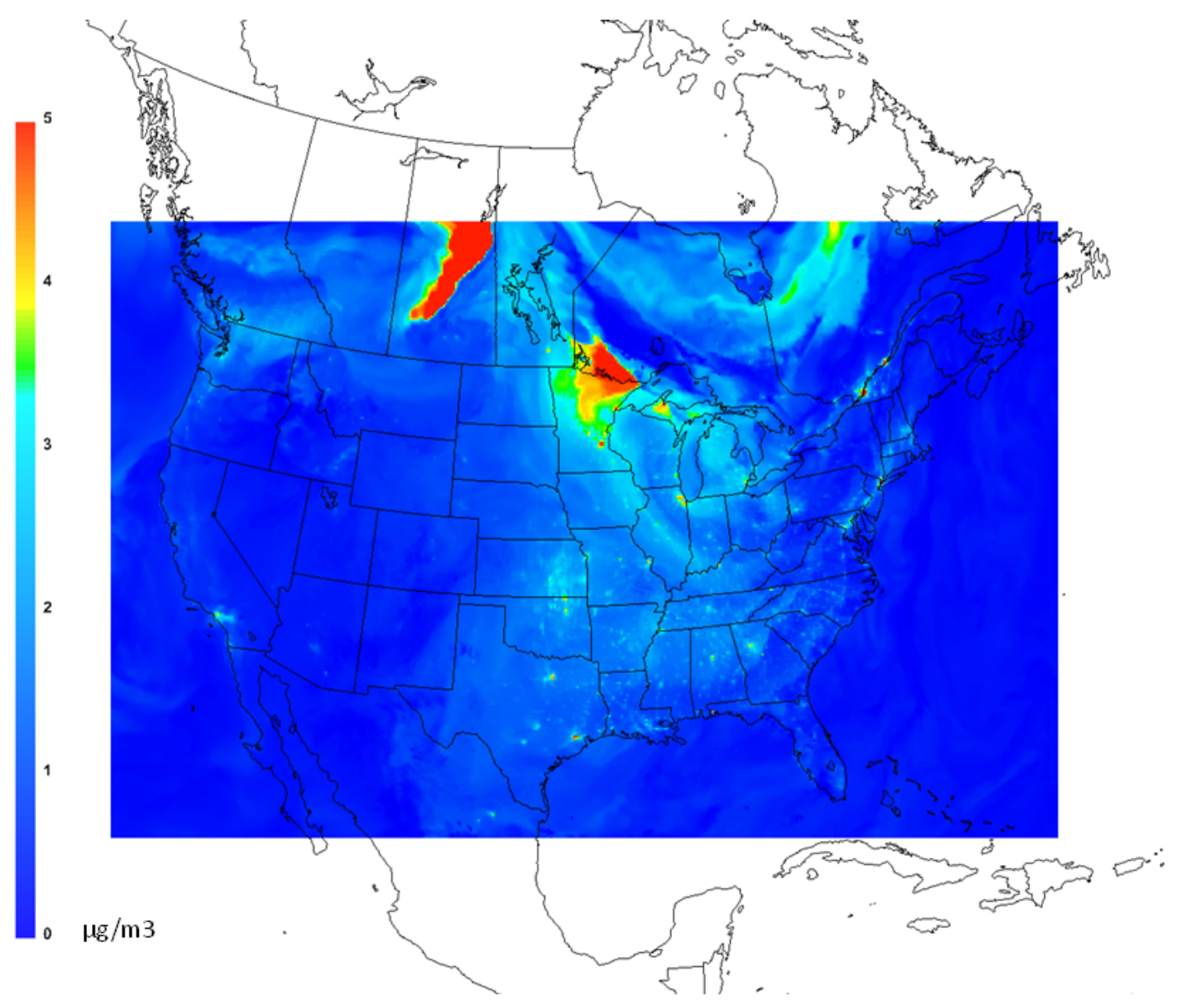


Figure 11

a) Summer Season

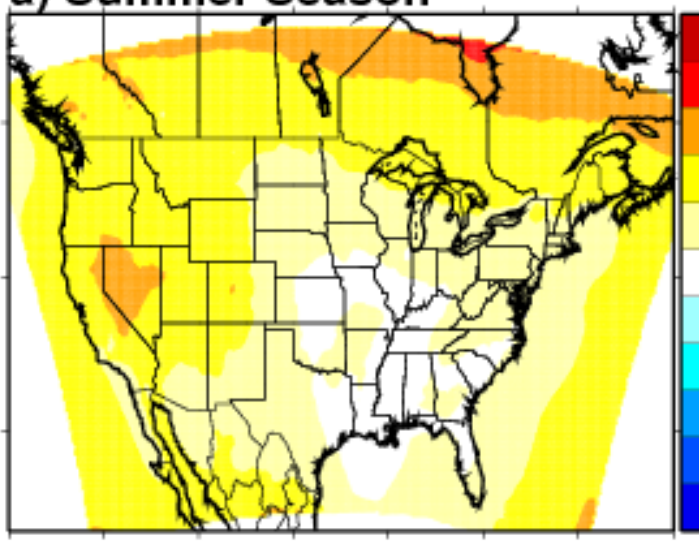

c) Winter Season

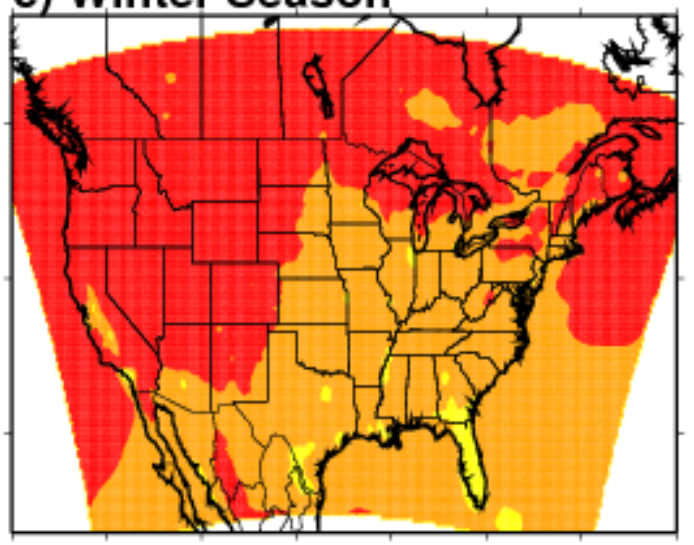

b) Fall Season

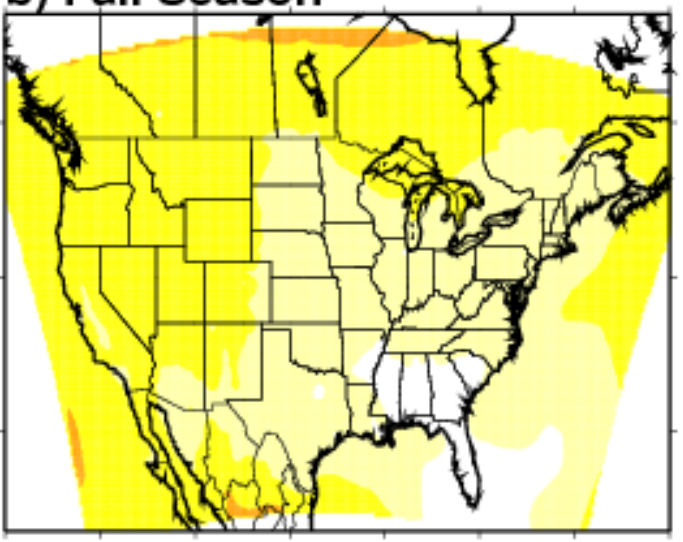

d)Spring Season

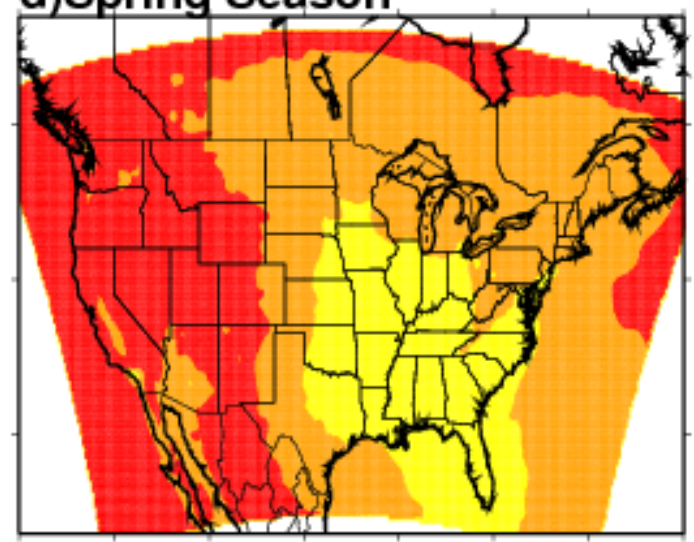


Figure 12.
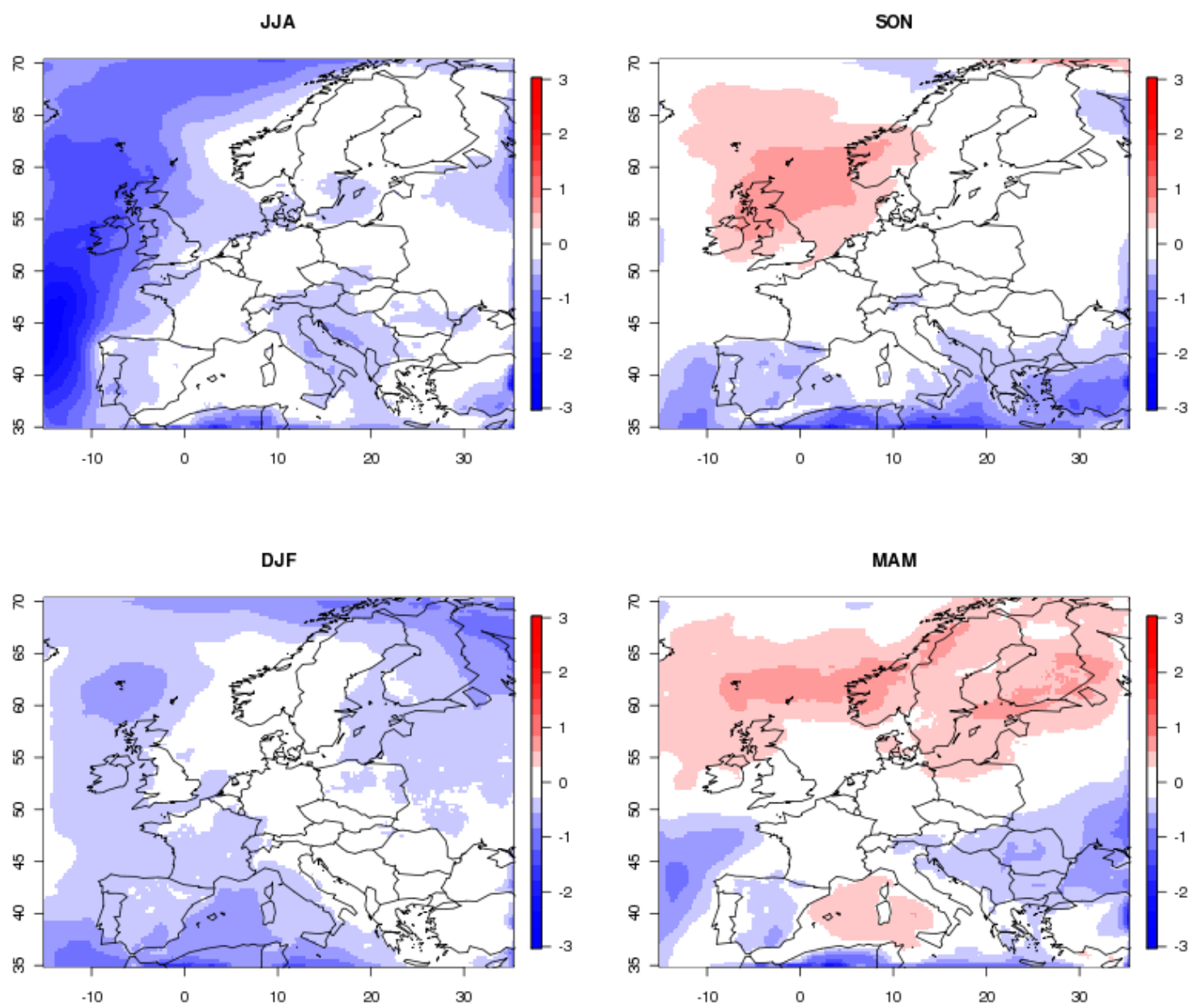
Figure 13.
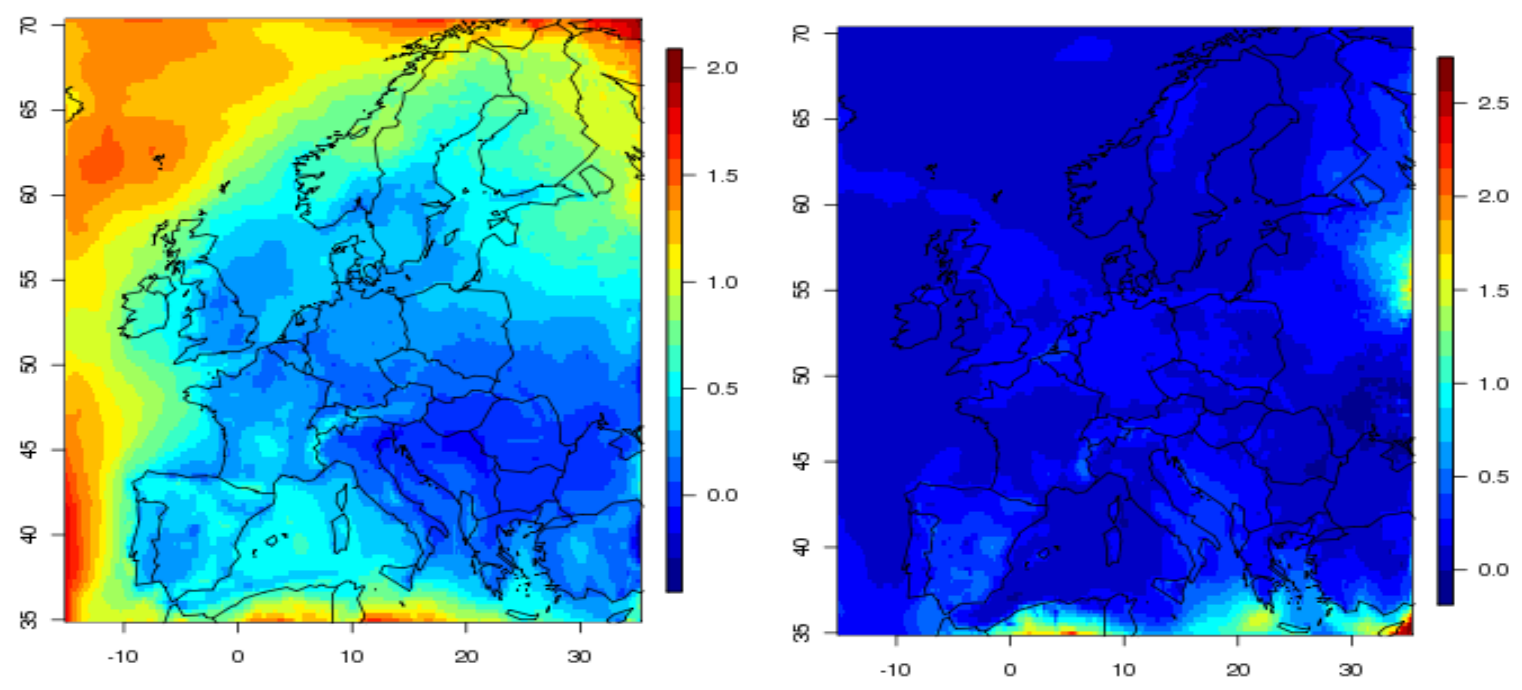
Figure 14.

(a) Observed $\mathrm{O}_{3}$ mixing ratio - Lerwick (UK), 2006

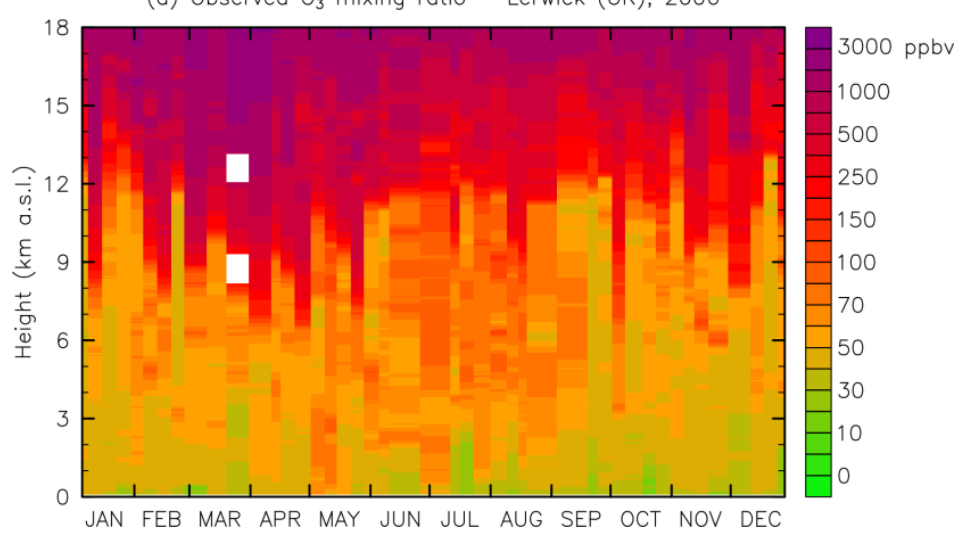

(b) Simulated $\mathrm{O}_{3}$ mixing ratio, 2006 - GEMS

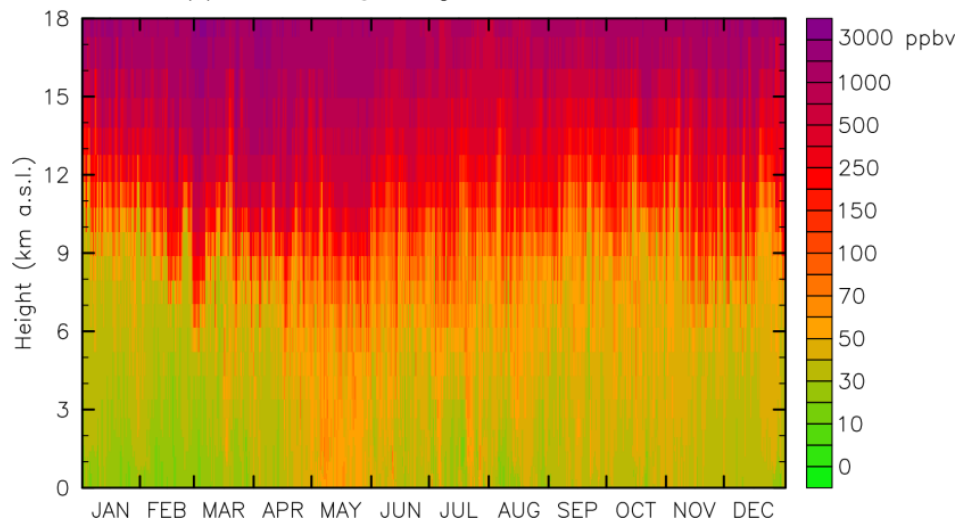

(c) Simulated $\mathrm{O}_{3}$ mixing ratio, 2006 - GEOS-Chem

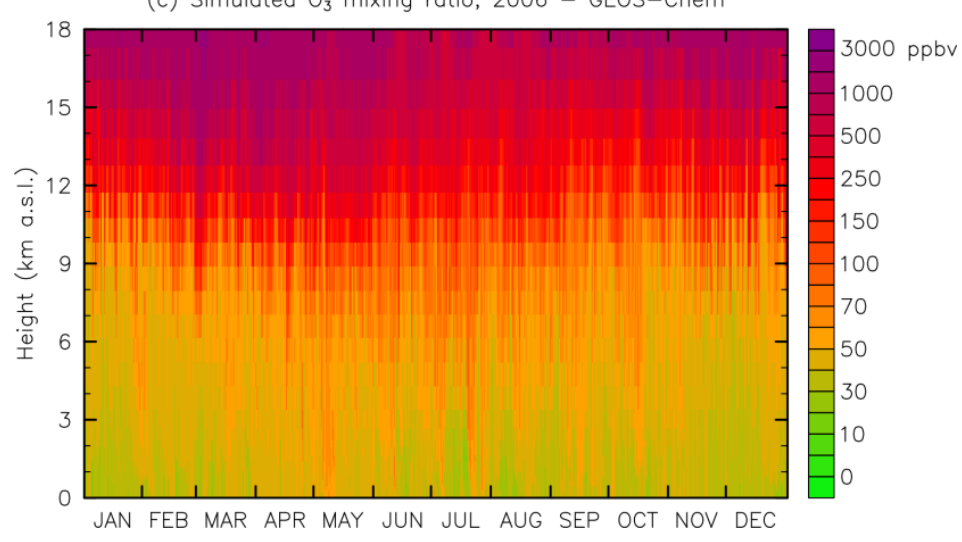


Figure 15.

(a) Mace Head, 2006 - GEMS

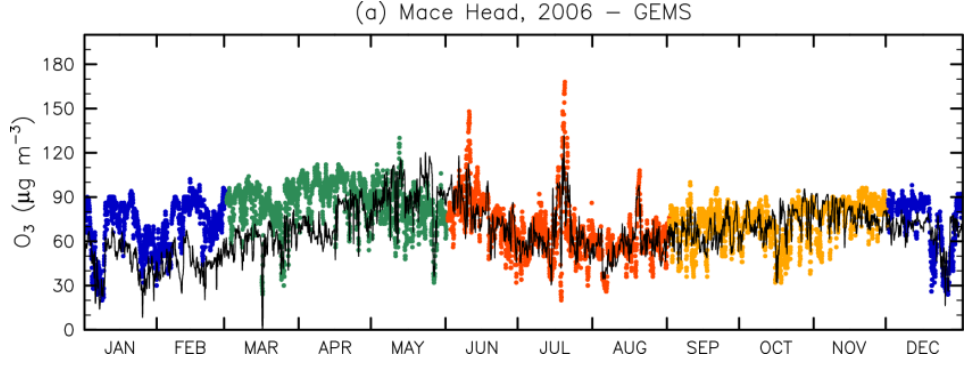

(b) Mace Head, 2006 - GEOS-Chem

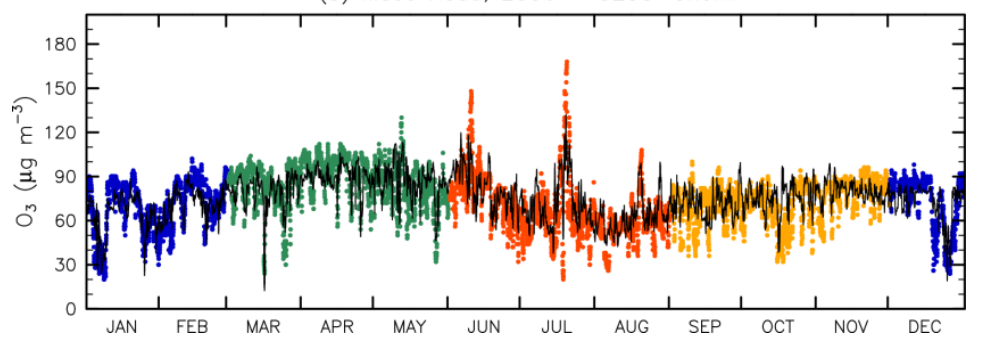

